V. 12 N. 1

JAN-ABR 2016

ISSN 2317-6172

Recebido: 14.12.2014

Aprovado: 02.02.2016

DOI: http://dx.doi.org/10.1590/ 2317-6172201609

1 Universidade Federal do Rio de Janeiro Rio de Janeiro - RJ - Brasil

2 Universidade da Amazônia Belém - PA - Brasil

3 Universidade Estácio de Sá Rio de Janeiro - RJ - Brasil

4 Universidade Federal do Rio de Janeiro Rio de Janeiro - RJ - Brasil

\section{Judicialização do federalismo e federalismo formal}

\author{
JUDICIALIZATION OF FEDERALISM AND FORMAL FEDERALISM \\ Henrique Rangel ${ }^{1}$, Alexandre Fadel ${ }^{2}$, Bianca Neri ${ }^{3}$ \\ e Carlos Bolonha
}

\section{Resumo}

0 presente artigo promove uma análise comparativa dos modelos de federalismo norte-americano e brasileiro, traçando-se como critério de avaliação seus respectivos níveis de centralização política e considerando o problema central adotado pela pesquisa, que consiste na aproximação do modelo federativo brasileiro de um regime unitário. A confrontação parte de uma seleção dos três precedentes recentes mais paradigmáticos da Suprema Corte norte-americana em matéria de federalismo, trazendo as controvérsias enfrentadas por esses julgadores ao contexto normativo brasileiro. Sustenta-se a hipótese de que a quantidade de critérios alternativos de federalização e a forma com que estes são afirmados em sede jurisdicional são determinantes no entendimento dos níveis de centralização alcançados em cada modelo. 0 objetivo do presente trabalho não é somente afirmar que o federalismo formal encontrado no Brasil é mais centralizado, mas indicar como o modelo jurisdicional observado nos Estados Unidos consegue preservar um regime coerente e de ampla autonomia dos estados pela marcante atuação da Suprema Corte.

\section{Palavras-chave}

Desenhos constitucionais; federalismo; Suprema Corte norte-americana; cláusula de comércio; competências legislativas.

\begin{abstract}
This paper promotes a comparative analysis of American and Brazilian models of federalism assuming their levels of political centralization as main criterion. The central problem faced herein is the Brazilian approach of Unitarian regime. The confrontation starts from the selection of the three most paradigmatic precedents of the recent U.S. Supreme Court's concerns over federalism and continues bringing its practical controversies to the Brazilian normative context. The hypothesis holds that the amount of alternative criteria of federalization, and the way they are upheld on judicial review, are crucial to understand the levels of political centralization achieved in each model. The aim of this work is rather indicate how jurisdictional federalism found in United States can preserve a consistent model, with States robustly autonomous, than only argue the more centralized character of Brazilian formal federalism.
\end{abstract}

\section{Keywords}

Constitutional design; federalism; U.S. Supreme Court; commerce clause; legislative authority. 


\section{INTRODUÇÃO}

A Constituição da República Federativa do Brasil de 1988 (CRFB/88) instituiu um novo ordenamento jurídico no país. Renovando seu espectro de normas constitucionais, foram estabelecidos aqueles desenhos institucionais em larga escala responsáveis por estruturar um Estado orientado a ser democrático e de direito. ${ }^{1}$ Um desses desenhos institucionais em larga escala estabelecidos permanentemente pela CRFB/88 foi a forma federativa de Estado. ${ }^{2}$ Embora a estrutura tenha sido mantida desde o regime político-jurídico anterior,

1 No campo dos desenhos institucionais, há uma classificação baseada na escala - pequena ou larga -, diferenciando mecanismos institucionais de arranjos institucionais. A principal função dessa classificação está associada ao objetivo de promover alterações no desenho existente. Em tese, quanto maior a escala do desenho, mais difícil e custoso seria alterá-lo. Grandes arranjos institucionais, devido a sua reiterada e contínua utilização pelos agentes institucionais e à forte associação entre eles e o regime democrático promovida pela população, não podem ser extintos sem que haja uma profunda resistência ou grandes questionamentos relativos à legitimidade da mudança. Isso não significa que um desenho institucional de larga escala não seja passível de modificação ao longo da história. Na verdade, o que se defende é que problemas institucionais existem, mas combater tais dificuldades provocando expressivas alterações em tradicionais arranjos institucionais estabelecidos pode não ser a saída mais estratégica. Nestes termos: "Why focus on institutional design writ small? The principal reason is that '[d]emocracy is inherently a device for regulating marginal political conflicts.' This reads as an essentialist claim about the very concept of democracy; in context, however, it is a claim about the insuperable costs of changing the large-scale structures of an ongoing democratic order on which the whole society has coordinated. The fact is that in most democratic polities, the basic constitutional arrangements are no longer up for grabs. New polities forming new constitutions may be interested in the basic structures of constitutionalism, as evident in the wave of Eastern European constitution-making in the 1990s. In places and times like that, there is a point to large-scale debates over parliamentary systems versus the separation of executive and legislative powers, or over proportional representation versus other representative forms. In the consolidated democracies of North America, the British Commonwealth, Western Europe and Scandinavia, and parts of Latin America and Eastern Europe, however, small-scale institutional design is all that is on offer. It is unlikely in the extreme that the United States will switch to a parliamentary system, or that the United Kingdom will switch to a system of separated powers" (VERMEULE, 2011a, p. 2-3). O federalismo representa um arranjo institucional e, apesar da histórica tradição centralizadora que predomina no Brasil, essa forma de Estado foi mantida pelo novo ordenamento jurídico. Nada impede, no entanto, que o referencial acima seja utilizado como inspiração para os designers brasileiros. Nosso modelo federativo possui profundos problemas, mas isso não significa que deverá ser abolido e substituído por uma forma unitária de Estado. Ao contrário, mecanismos institucionais devem ser buscados como uma saída estratégica para superar as dificuldades que emergem frequentemente nesse âmbito.

2 Normativamente, a forma federativa de Estado foi estabelecida pelo art. $1^{\circ}$, caput, CRFB/88 ao definir: “Art. 1 ${ }^{\circ}$. A República Federativa do Brasil, formada pela união indissolúvel dos Estados e Municípios e do Distrito Federal, constitui-se em Estado Democrático de Direito e tem como fundamentos: [...]”. Seu caráter permanente, por sua vez, deriva das regras que representam os limites materiais ao poder de reforma: "Art. 60. A Constituição poderá ser emendada mediante proposta: [...] $4^{\circ}$ - Não será objeto de deliberação a proposta de emenda tendente a abolir: I - a forma federativa de Estado; [...] ”. 
o atual modelo brasileiro apresentou um traço marcante ao qualificar os municípios como ente federativo - ou, como preferem alguns constitucionalistas, entidade com autonomia político-constitucional. ${ }^{3} \mathrm{Na}$ tradicional teoria do Estado, tais estruturas não costumavam ser encontradas com essa qualidade de ente federativo - ou com autonomia político-constitucional -, o que o torna um modelo peculiar que os doutrinadores convencionaram designar federalismo de terceiro grau ou de terceira ordem (MEIRELLES, 2006).

O federalismo não representa um exemplo isolado no Brasil de desenho institucional peculiar ou pouco convencional. ${ }^{4}$ Diversas estruturas do país, inclusive de larga escala, são criticadas como importações de teorias, conceitos ou institutos de modo pouco racional. O controle de constitucionalidade brasileiro, por exemplo, é atualmente caracterizado como híbrido, devido à importação de referenciais norte-americanos do judicial review que coabitam o cenário das competências jurisdicionais com as concepções austríacas de controle abstrato. Historicamente, também foram experimentados modelos inusitados de separação de poderes, com a presença do arbitrário Poder Moderador, concentrado na

3 Do ponto de vista normativo, os municípios fazem parte da organização político-administrativa da República: "Art. 18. A organização político-administrativa da República Federativa do Brasil compreende a União, os Estados, o Distrito Federal e os Municípios, todos autônomos, nos termos desta Constituição. [...]”. Alguns constitucionalistas, mantendo a tradicional concepção de federalismo, defendem que os municípios no Brasil não alcançam a natureza de ente federativo, gozando apenas de prerrogativas expressas da Constituição que corresponderiam a uma autonomia político-administrativa. "Essa é uma tese equivocada, que parte de premissas que não podem levar à conclusão pretendida. Não é porque uma entidade territorial tenha autonomia político-constitucional que necessariamente integre o conceito de entidade federativa. Nem o Município é essencial ao conceito de federação brasileira. Não existe federação de Municípios. Existe federação de Estados. Estes é que são essenciais ao conceito de qualquer federação" (SILVA, 2007, p. 474-475). Na verdade, o que a teoria clássica do Estado atribui aos entes federativos é a autonomia para aparelhar seu governo - administrativa -; para eleger seus governantes - política -; e para produzir as leis de sua competência - legislativa. Se o federalismo exige que os entes federativos detenham essas três formas de autonomia, não há razões para distinguir a natureza de ente federativo dos municípios no Brasil de sua suposta autonomia político-constitucional. A CRFB/88 confere aos municípios - mais do que autonomia política - todas as prerrogativas exigidas pela tradicional teoria do Estado, não sendo plausível excluí-los da estrutura federativa brasileira. Nesse sentido, representando uma posição contrária à anterior: "O Município brasileiro é entidade estatal integrante da Federação. Essa integração é uma peculiaridade nossa, pois em nenhum outro Estado Soberano se encontra o Município como peça do regime federativo, constitucionalmente reconhecida. Dessa posição singular do nosso Município é que resulta a sua autonomia político-administrativa, diversamente do que ocorre nas demais Federações, em que os municípios são circunscrições territoriais meramente administrativas" (MEIRELLES, 1991, p. 663).

4 Para os fins do presente trabalho, será adotado como definição de "federalismo" o que indica Erwin Chemerinsky, apenas acrescentando, para o caso brasileiro, a presença de administrações municipais: "By 'federalism,' I simply mean the allocation of power between the federal and the state governments. More specifically, federalism [...] refers to the extent to which consideration of state government autonomy has been and should be used by the judiciary as a limit on federal power" (CHEMERINSKY, 1995, p. 504). 
figura do imperador, e de parlamentarismo - que se difundiu como às avessas pelo fato de o primeiro-ministro não ser nomeado e destituído pelo Parlamento, e sim pelo imperador. ${ }^{\mathbf{5}}$ Diante desse quadro de construção de desenhos institucionais, no mínimo, heterodoxos, o federalismo brasileiro parece ser mais uma excepcionalidade de nossa história políticojurídica. Apesar de a forma federalista ter sido hegemônica no Brasil após a Proclamação da República, seu curso histórico apresentou suntuosas oscilações entre centralização e descentralização política. Nesses meandros, historiadores e constitucionalistas costumam se referir ao modelo federativo brasileiro como caracterizado por uma forte centralização do poder político sob o domínio da União Federal. Isso representa uma excepcionalidade se comparado com modelos mais tradicionais de forma federativa, sobretudo quando traçado um comparativo com os Estados Unidos da América (EUA), onde um modelo que confere expressiva autonomia aos estados-membros foi "fundado" e significativamente consolidado pela força da tradição. ${ }^{6}$

Algumas distinções podem ser demarcadas ao se adotarem as dinâmicas federativas brasileira e norte-americana como objetos de análise. Assim, este trabalho aborda, especificamente, a União Federal no Brasil e nos EUA e suas correspondentes relações mantidas com os demais entes federativos. Em tal abordagem, receberá especial destaque o tratamento atribuído à matéria pelos precedentes paradigmáticos da Suprema Corte norte-americana como ponto de partida da avaliação do nível de centralização encontrada em cada um dos países. Tais precedentes não necessariamente terão correspondência com casos do Supremo

5 A previsão normativa do Poder Moderador se encontra na Constituição Política do Império do Brazil de 1824: "Art. 98. O Poder Moderador é a chave de toda a organisação Politica, e é delegado privativamente ao Imperador, como Chefe Supremo da Nação, e seu Primeiro Representante, para que incessantemente vele sobre a manutenção da Independencia, equilibrio, e harmonia dos mais Poderes Politicos”. Com base nessa mesma Constituição, após a instituição do regime de governo parlamentarista no Segundo Império, o Poder Moderador tornou-se o responsável por intervir na figura do primeiro-ministro, em vez de o mesmo ser nomeado e destituído pelos membros da legislatura: "Art. 101. O Imperador exerce o Poder Moderador [...] VI. Nomeando, e demittindo livremente os Ministros de Estado [...]”.

6 A fundação da forma federativa norte-americana foi bem-sucedida devido ao sucesso da doutrina exercida pelos Pais Fundadores em um contexto político-econômico de forte disputa territorial entre o Norte das Treze Colônias, estruturado com base na indústria protecionista, especialmente em relação ao ímpeto de produção e exportação britânica, e o Sul, dependente do liberalismo alfandegário que beneficiava sua economia agrícola voltada à exportação. Tais conjunturas permitiram que um modelo de ampla autonomia pudesse ser consolidado nos EUA, que, mesmo após o decurso de séculos, ainda pode ser observado (HAMILTON; MADISON; JAY, 2001). No Brasil, o evento histórico que ficou conhecido como Proclamação da República, formalizado através do Decreto n. 1, de 15 de novembro de 1889, encerrou o período imperial. Esse ato, no entanto, não partiu da população como um todo, tendo sido declarado por uma elite militar. Prestigiosas pesquisas historiográficas indicam que, enquanto o ato era realizado no centro do Rio de Janeiro, o povo apenas assistia ao evento, em estado bestializado (CARVALHO, 1987). 
Tribunal Federal (STF), razão pela qual serão confrontados, predominantemente, com as disposições normativas do regime federativo brasileiro. ${ }^{7}$

Por meio dessa avaliação comparativa, sustenta-se a seguinte hipótese: o nível de centralização nos modelos norte-americano e brasileiro pode ser avaliado de acordo com o número de critérios normativos de federalização e sua predominância na atividade jurisdicional. Para fins semânticos, o termo "critérios normativos de federalização" deverá ser compreendido como poderes ou competências legislativas formalmente atribuídos à esfera federal pela correspondente Constituição. ${ }^{8}$ De um lado, a quantidade dessas hipóteses normativas que, expressamente, transformam certos assuntos ou matérias em questões federais fornecem um forte indício do nível de centralização dessa forma de Estado. ${ }^{9}$ Quando o regime prevê exaustivos critérios de federalização, há um significativo indicativo de centralização. De outro lado, é necessário também analisar o tratamento que tais critérios de federalização recebem quando suscitado algum dilema federativo - alguma controvérsia prática envolvendo as entidades desse desenho institucional. Se um pequeno número de critérios se destaca como parâmetro determinante para solucionar os dilemas federativos do Estado, defende-se que a centralização do regime parece ser reduzida. O fato de um ou poucos critérios servirem de instrumento para transferência do assunto ou matéria à esfera federal na atividade judicial reduz a própria possibilidade de federalização no país. Quando a prática judicial indica que o uso de critérios de federalização é aleatório ou impede que alguns se tornem predominantes, significa que há um amplo espectro de possibilidades para que a União Federal possa oportunamente avocar a controvérsia para

7 Para uma pesquisa sobre o papel das Cortes na construção do desenho da federação tendo especificamente o Brasil como referência, ver Araújo (2009).

8 Particularmente, os critérios normativos de federalização dos EUA são encontrados na seção 8 do art. I da Constituição desse país, enquanto os pertinentes ao Brasil se concentram, basicamente, no art. 22 da $\mathrm{CRFB} / 88$.

9 Para os propósitos da presente pesquisa, o termo "centralização política" deverá ser compreendido de modo diretamente relacionado aos critérios de federalização existente naquele respectivo país. Embora outras definições possam ser encontradas na ciência e na teoria políticas, na teoria do Estado e na historiografia, os níveis de centralização da autoridade para legislar será aqui apurado de acordo com os seguintes critérios: (i) pluralidade de critérios de federalização, (ii) generalidade dos critérios frequentemente aplicados e (iii) variabilidade. Quanto mais critérios houver à disposição das autoridades federais, mais alternativas estão à disposição para avocar controvérsias do interesse de representantes que atuam em sua esfera. Quanto mais genéricos os critérios utilizados, maior é o desafio para estados preservarem sua autoridade legislativa. Por fim, quando os critérios de federalização previstos dificultam a variabilidade de seu resultado, ou seja, operam mediante presunções legais - como "compete à União legislar, privativamente, em matéria de direito penal" -, o ônus argumentativo requerido para deslocar a questão para a União Federal é menor do que o observado em critérios baseados na concreta demonstração de qual ente federativo deverá exercer legitimamente aquele poder. Uma comparação mais detalhada dessa relação entre centralização política e federalismo e de como as Cortes podem interferir nesse processo poderá ser encontrada na seção que antecede a conclusão. 
o âmbito de seu poder. Por fim, critérios cuja abrangência do escopo seja suficientemente ampla para retirar determinada questão do plano das discussões, tornando presumido o interesse da União Federal, sem que haja um rigoroso enfrentamento ou uma deliberação, admitem-se como centralizadores.

Para testar essa hipótese, parte-se de uma metodologia temporalmente delimitada ao interregno de 1994 a 2014 para comparar os precedentes norte-americanos mais paradigmáticos sobre sistema federativo com a dinâmica brasileira. Os três precedentes selecionados, de ampla difusão no meio jurídico norte-americano, são United States vs. Morrison (2000), Gonzales vs. Raich (2005) e United States vs. Lopez (1995). ${ }^{10}$ Os casos serão analisados a partir do

10 Os casos serão suficientemente apresentados ao longo do texto, esclarecendo o quadro fático que fornece o pano de fundo da discussão, bem como a decisão tomada em cada uma das controvérsias. Cf. United States vs. Morrison, 529 U.S. 598 (2000); Gonzales vs. Raich, 545 U.S. 1 (2005); e United States vs. Lopez, 514 U.S. 549 (1995). Reforçando a relevância desses três casos para se discutir federalismo diante da atuação recente da Suprema Corte norte-americana (GRAGLIA, 2008). Tais precedentes são compreendidos, entre constitucionalistas e cientistas políticos norte-americanos, como responsáveis por reorganizar a relação entre legislação federal e autonomia estadual no país. Cunhou-se, inclusive, um termo referente a este período da Corte, indicando que o federalismo teria sido "ressucitado" (federalism revival) (DEVINS, 2007). Em grande parte, essa mudança na abordagem do federalismo dentro da Corte de Rehnquist decorre de um retorno à prática de invalidar leis federais em nome do regime federalista. Até que a Suprema Corte decidisse o precedente United States vs. Lopez (1995), o país passou por quase sessenta anos sem invalidar uma lei federal alegando violação à chamada cláusula de comércio (McGIMSEY, 2002; ALTHOUSE, 1996). Na metodologia da presente pesquisa, o critério adotado para selecioná-los se restringe a dilemas federativos formados ao redor do exercício de competências legislativas. Com isso, a pesquisa se concentra somente nos casos em que a Suprema Corte foi provocada a responder "se o Congresso excedeu sua autoridade ao legislar" ou se "o Estado violou a autoridade do Congresso ao legislar". Outros casos foram enfrentados pela Suprema Corte, entre 1994 e 2014, abordando questões federativas, mas somente os três precedentes acima se concentraram em autoridade para legislar. Entre os casos da Suprema Corte que suscitaram dilema federativo, talvez o mais recente seja National Federation of Independent Businesses vs. Sebelius, 567 U.S. (2012). Nesse precedente, havia dois principais questionamentos. No primeiro, era questionado o poder do Congresso para editar o Patient Protection and Affordable Care Act of 2010, popularizado como Obama Care. Essa competência legislativa questionada, todavia, estava relacionada à taxing and spending clause e, portanto, discutia-se os limites da atuação do governo em relação ao indivíduo - devido à tributação de cidadãos que não participassem do Obama Care. Buscava-se entender se o poder existia, não sobre quem era seu titular. Somente na segunda indagação estava o dilema federativo. A referida lei federal foi invalidada porque estabelecia encargos excessivos aos estados que não aceitassem seus termos, o que violaria sua autonomia administrativa. Não se debateu a competência legislativa entre entes federativos - apenas autonomia administrativa. Em precedente anterior, Nevada Department of Human Resources vs. Hibbs, 538 U.S. 721 (2003), indagava-se a possibilidade de um estado responder a obrigações de indenizar indivíduos diante de cortes federais por violar a Family and Medical Leave Act of 1993, uma lei federal. Não havia questionamento de competências legislativas. Em Reno vs. Condon, 528 U.S. 141 (2000), a Corte manteve a validade da Driver's Privacy Protection Act of 1994, que proibia estados de revelarem informações pessoais de motoristas. A lei tratava de privacidade, mas foi questionado se a medida ofendia o princípio federativo, obtendo-se uma resposta negativa por não haver violação da autonomia administrativa quando a lei não obriga estados a regulamentá-la ou a executá-la. A Corte de Rehnquist também enfrentou 
critério de federalização assumido pela Suprema Corte ao tomar sua decisão, para, posteriormente, traçar um comparativo com o Brasil, indicando um possível tratamento que a controvérsia poderia receber. De acordo com essa confrontação, será possível constatar se o critério apropriado em cada país seria indicativo do nível de centralização existente. Analisando-se os mencionados precedentes, julgados durante a Corte de Rehnquist, será possível constatar que há uma retomada da discussão do federalismo naquele país, embora suas decisões sejam constantemente avaliadas como conservadoras. ${ }^{11}$

O objetivo do presente artigo é reforçar a existência de uma expressiva centralização na forma federativa de Estado brasileira, acrescentando, porém, que esse fenômeno pode ser analisado a partir da atividade jurisdicional.

\section{ViolêNCIA MOTIVAdA POR GÊNero (UNITED STATES VS. MORRISON)}

No precedente United States vs. Morrison (2000), a Suprema Corte norte-americana recebeu uma reclamação de Christy Brzonkala, que alegou ter sofrido abuso sexual de dois estudantes do Instituto Politécnico de Virgínia, Antonio Morrison e James Crawford. Morrison, um

outra controvérisa em matéria de segurança pública, mas sem a repercussão de United States vs. Lopez (1995). O federalismo foi discutido, novamente, a partir de competências administrativas em Printz vs. United States, 521 U.S. 898 (1997). A Corte invalidou a Brady Handgun Violence Prevention Act of 1993, conhecida como Brady Bill, uma lei federal, porque determinava a autoridades policiais dos estados realizar verificação de antecedentes criminais de todo adquirente de pistolas ou revólveres. Não se questionou competência legislativa, mas a inadequação de lei federal ao, ainda que provisoriamente, estabelecer dever funcional a oficiais locais. Em United States Term Limits, Inc. vs. Thornton, 514 US 779 (1995), o dilema federativo consistia em um caso de princípio da simetria, não havendo disputa por autoridade legislativa. Estados foram impedidos de estabelecer limitações à reeleição de seus representantes. Antes de período definido pela metodologia, o debate sobre federalismo estava sensivelmente adormecido e os dilemas federativos enfrentados eram secundários às temáticas que chegavam à Corte. Há decisões anteriores a esse interregno, no entanto, que são abordadas no presente artigo devido à força vinculante que adquiriram em casos subsequentes. Os principais exemplos, advindos da Era New Deal, são NLRB vs. Jones \&Laughlin Steel Corp., 301 U.S. 1 (1937), e Wickard vs. Filburn, 317 U.S. 111 (1942), principais expoentes da moderna concepção da commerce clause, predominante nos três precedentes selecionados pela presente pesquisa. À época a função dessa cláusula e de seu novo consectário, o substancial impacto no comércio interestadual, era aumentar o poder da União Federal, notadamente em função dos planos econômicos intervencionistas de Franklin Roosevelt, mas, nos casos mais recentes, o efeito oposto também pôde ser observado com frequência - como em United States vs. Lopes (1995) e em United States vs. Morrison (2000). Isso demonstra o quanto o critério de federalização predominante nos dilemas norte-americanos revela variabilidade e, assim, nem sempre favorece a centralização política.

11 "The Rehnquist Court was a conservative Court, and conservative Courts like federalism." (YOUNG, 2006, p. 874). Complementando, ver Tushnet (2000). Para compreender as concepções de federalismo fixo (fixed federalism) e federalismo flexível (flexible federalism) que dividiam o Congresso, respectivamente apoiadas por republicanos e democratas, e como tal divisão refletiu nas decisões da Corte de Rehnquist e em seu conservadorismo, ver Clayton e Pickerill (2004). 
dos alunos que teriam cometido o abuso contra Brzonkala, foi julgado culpado pela administração universitária, que lhe aplicou como penalidade imediata a suspensão por dois semestres. Morrison recorreu administrativamente e conseguiu afastar sua punição, reputada pelo instituto do estado de Virgínia como "excessiva". Brzonkala abandonou o instituto e ajuizou uma demanda judicial contra Morrison, Crawford e o Instituto Politécnico de Virgínia, recorrendo a disposições legais da Violence Against Women Act of 1994 (VAWA), que, sob a alegação de violência de gênero, permitiria a ela acionar remédios civis instituídos pela esfera federal. ${ }^{12}$ Morrison e Crawford, em resposta, alegaram inconstitucionalidade dos remédios lançados por Brzonkala por faltar ao Congresso autoridade para regulamentar a matéria, ocasião em que os EUA passaram a intervir na controvérsia a fim de defender a constitucionalidade da norma federal. Brzonkala sucumbiu, tanto na instância inicial da Corte Distrital, quanto em sede recursal na Corte de Apelação, e, devido à inconstitucionalidade declarada de norma federal, os EUA conduziram o caso via certiorari à Suprema Corte. ${ }^{13}$

Após a Corte de Apelação manter a decisão de primeiro grau, o caso chegou à Suprema Corte norte-americana devido à tentativa dos EUA de a reformarem. No julgamento desse marcante precedente, a Suprema Corte tomou a decisão, com uma divisão 5-4, de manter o julgado pela Corte Distrital ao declarar a inconstitucionalidade das disposições da VAWA. A opinião da Corte foi liderada pelo Chief Justice William Rehnquist, com o apoio dos Justices frequentemente reputados como conservadores Clarence Thomas e Antonin Scalia - que ofereceu opinião concorrente por discordar dos fundamentos majoritários - e dos que, geralmente, são considerados swing vote, oscilando seus posicionamentos entre democratas e republicanos, Sandra O'Connor e Anthony Kennedy. ${ }^{14}$

12 De acordo com as disposições da VAWA: "[a]ll persons within the United States shall have the right to be free from crimes of violence motivated by gender”. Cf. United States vs. Morrison, 529 U.S. 598, p. 5 (2000) - opinião da Corte.

13 Existem algumas formas de se alcançar a jurisdição da Suprema Corte norte-americana, conforme disposto em seu "regimento interno" - Rules of Supreme Court of United States (disponível em: < http: / / www. supremecourt.gov/ctrules/ctrules.aspx>; acesso em: 9 fev. 2016). O certiorari, no entanto, tem se mostrado contemporaneamente como o modo predominante de ingresso nessa Corte. Quando inconformadas com as decisões proferidas pelas Cortes de Apelação, as partes podem produzir um petition of certiorari, que será analisado pelo conjunto de assessores dos Justices - conhecidos como pool of clerks ou como pool of certiorari -, responsáveis por lhes relatar o caso e lhes aconselhar quanto à admissão do certiorari. Quando aceita a petição, os Justices esclarecem as razões da admissão em um documento conhecido como writ of certiorari. Para maiores detalhes e uma comparação entre o regime do certiorari e o regime da repercussão geral do recurso extraordinário no Supremo Tribunal Federal brasileiro, ver Berman (2009).

14 É muito comum, entre constitucionalistas e cientistas políticos norte-americanos, classificar a orientação que os Justices costumam adotar de modo relativamente padronizado em suas decisões. Em geral, a distinção ocorre em termos de "republicanos", para aqueles com compreensões mais conservadoras, comportamento de 
Basicamente, a Corte decidiu que a legislação federal suscitada por Brzonkala "não pode ser sustentada sob a cláusula de comércio (commerce clause) ou sob o quinto parágrafo da Décima Quarta Emenda”. ${ }^{15}$ Embora dois argumentos tenham sido mencionados acima, a análise da opinião da Corte, liderada por Rehnquist, permite constatar que o critério de federalização considerado determinante para a decisão foi a cláusula de comércio. ${ }^{16}$ Essa cláusula se encontra no art. I, seção 8, da Constituição dos EUA, estabelecendo que “o Congresso deve ter o poder de regular o comércio com nações estrangeiras, entre vários Estados e com tribos indígenas". ${ }^{17}$ Com isso, o sentido original da cláusula de comércio norte-americana

autocontenção mais acentuado e entendimentos econômicos sensivelmente mais liberais, e de "democratas", para os julgadores mais progressistas, de comportamento mais ousado e ativista e entendimentos econômicos marcantemente intervencionistas. Para uma compreensão mais profunda das divisões que marcaram a Corte de Rehnquist, ver Tushnet (2005). Nem todos os agentes, entretanto, conseguem manter um padrão de elevada estabilidade e previsibilidade, oscilando intermitentemente entre os quadros compreendidos como "republicano" e "democrata". Tais julgadores têm recebido a denominação de swing vote, devido a seu posicionamento variável nas decisões da Suprema Corte norte-americana e, muitas vezes, determinantes no desfecho dos casos mais polêmicos e que ensejam maior fragmentação da Corte: 'The 'center' of the Court; the Court's 'middle'; the 'swing' Justice; the 'pivotal' Justice; and the most 'powerful' Justice. Legal commentators regularly invoke these terms to characterize the Justice who is crucial to the outcome of a case and, thus, to the establishment of public policy. Social scientists, though, tend to use only one: the 'median' Justice, that is, the Justice in the middle of a distribution of Justices, such that (in an ideological distribution, for example) half the Justices are to the right of (more 'conservative' than) the median and half are to the left of (more 'liberal' than) the median” (MARTIN; QUINN; EPSTEIN, 2005, p. 1276-1277). De acordo com essas três possíveis classificações - e considerando a composição observada nos precedentes abordados pelo presente artigo -, Anthony Kennedy é considerado o maior exemplo de swing vote, seguido pela já aposentada Sandra O'Connor. "Like his swing-vote predecessors Justices Powell and O'Connor, Kennedy is feeling the pressure associated with being the middle Justice on a divided Court." (GERKEN, 2007, p. 104). São classificados como "republicanos" os radicais conservadores Antonin Scalia e Clarence Thomas, além do Chief Justice William Rehnquist, ao passo que John Paul Stevens é indicado como maior representante da ala "democrata", ao lado do pragmatista Stephen Breyer, de David Souter e de Ruth Ginsburg. Em geral, os swing votes, durante a Corte de Rehnquist, apresentaram uma forte tendência em acompanhar os "republicanos". Kennedy ainda mantém esse posicionamento dentro da Corte, conforme se pode observar na recente publicação do constitucionalista Erwin Chemerisnky: "Once more, Justice Kennedy was the justice most often in the majority, being in the majority in 94\% of the cases decided. Once more, Justice Kennedy was most often in the majority in the 5-4 decisions, being in the majority in every 5-4 ruling of the term" (CHEMERINSKY, 2014, p. 1).

15 Tradução livre de passagem a seguir: "Held: Section 13981 cannot be sustained under the Commerce Clause or $\S 5$ of the Fourteenth Amendment” (grifo no original). Cf. United States vs. Morrison, 529 U.S. 598, p. 1 (2000) - Syllabus.

16 O envolvimento da controvérsia com a Décima Quarta Emenda não alcançou a mesma relevância e repercussão que o parâmetro da cláusula de comércio, uma vez que a violação à equal protection clause foi sustentada pelos EUA apenas como pedido alternativo, hipótese também afastada pela Corte.

17 De acordo com a Constituição dos EUA, art. I, seção 8: "The Congress shall have Power [...] To regulate Commerce with foreign Nations, and among the several States, and with the Indian Tribes; [...]” (grifo nosso). 
visava federalizar três situações comerciais distintas, mas a última delas perdeu relevância e aplicabilidade com o decurso do tempo. Atualmente, a maior parte de alegações de violação ou excessos cometidos em relação à cláusula de comércio se apresentam sob a forma do comércio interestadual - como ocorreu em United States vs. Morrison (2000).

Os membros da Suprema Corte foram provocados a se pronunciar acerca do cometimento de excesso por parte do Congresso ao dispor do poder constitucional previsto na cláusula de comércio do art. I, seção 8, da Constituição dos EUA. Questionava-se, assim, quais seriam os limites da "autoridade" da competência legislativa da União Federal com base nesse critério normativo de federalização. ${ }^{18}$ A solução do dilema federativo dependia do estabelecimento de um critério normativo que indicasse quais seriam os limites de autoridade do Congresso e, portanto, se houve, efetivamente, excesso ao se aprovar a norma federal suscitada por Brzonkala - VAWA. O limite de autoridade do Congresso para legislar acerca dessa matéria foi submetido, pois, a uma técnica recorrente nos precedentes mais recentes da Suprema Corte: tentar identificar uma relação entre a situação regulamentada pela norma federal e seu substancial impacto no comércio interestadual. ${ }^{19}$

18 O termo "autoridade" empregado constantemente pela Suprema Corte pode ser avaliado sob a perspectiva dos desenhos institucionais. Quando os limites de atuação institucional são detalhadamente descritos em um texto normativo-constitucional, estabelecendo-se uma densa enumeração formal de competências e atribuições, a indeterminação e a incerteza são relativamente reduzidas. Porém, nem todo regime constitucional promove esse tipo de minuciosa descrição e distribuição dos poderes constitucionais como ocorre no Brasil. O modelo norte-americano é caracterizado por se basear em um texto normativo-constitucional sintético e que atribui poderes a suas instituições de modo mais aberto. Com isso, a indeterminação e a incerteza acerca dos limites de atuação das instituições podem conduzir a frequentes disputas pela autoridade política. Isso ocorre porque não há um sentido dado e previamente estabelecido, e sim que deverá ser deliberado para a construção de um entendimento ao redor daquele poder constitucional minimamente descrito. A partir de uma controvérsia prática ao redor da autoridade política para desempenhar aquele poder - no caso Morrison, um dilema federativo -, fica estabelecido um entendimento dentro da tradição de pensamento constitucional que servirá de precedente político para o país. Os limites de atuação institucional, na falta de um detalhado regime de distribuição formal de competências, portanto, são questionados de modo intermitente, gerando disputa pela autoridade no plano da política. No precedente Morrison, o caso foi levado à Suprema Corte, que se posicionou construindo um forte parâmetro político concernente aos limites de autoridade do Congresso norte-americano, a ser respeitado em dilemas federativos semelhantes: matéria de violência motivada por gênero sob a autoridade dos estados. Acerca de disputas pela autoridade política e sua característica de construir precedentes políticos no histórico constitucional do país, ver Posner e Vermeule (2011).

19 A cláusula de comércio, tradicionalmente, recebia uma aplicação altamente restrita pela Suprema Corte, mas seu escopo foi ampliado com o advento da denominada "era moderna" da cláusula de comércio, fundada com o precedente NLRB vs. Jones \& Laughlin Steel Corp., 301 U.S. 1 (1937). Com isso, há três categorias de atividade integrantes do poder do Congresso de regular o comércio: "As we observed in Lopez, modern Commerce Clause jurisprudence has 'identified three broad categories of activity that Congress may regulate under its commerce power.' [...] 'First, Congress may regulate the use of the channels of interstate commerce.' 
A cláusula de comércio foi apreciada pela Corte no caso Morrison de modo muito aproximado de seu precedente United States vs. Lopez (1995). ${ }^{20}$ Ao avaliar se a norma federal visava regular práticas com substantivo impacto no comércio interestadual, comentaram-se as alegações de "custos do crime" e de "produtividade nacional” feitas em Lopez e reiteradas em Morrison. No primeiro caso, argumenta-se que os custos do crime cometido são distribuídos à população genericamente, enquanto se argui, no segundo, que determinadas regiões podem se tornar pouco atrativas com o aumento dos índices de violência, reduzindo a produtividade local, por exemplo, em matéria de turismo. Ambas as alegações foram enfrentadas no caso Morrison e afastadas, haja vista que qualquer hipótese de crime violento estaria, desse modo, suscetível de federalização - mesmo posicionamento observado em Lopez. Com isso, eliminaram-se as possibilidades de substantivo impacto sobre o comércio interestadual. Ao final da deliberação, a opinião predominante da Corte estabeleceu que o objeto da norma federal declarada inconstitucional, violência motivada por gênero, não é atividade econômica, nem interfere substancialmente no plano do comércio interestadual. Tratando-se de uma forma de violência que alcança somente abrangência intraestadual, foi decidido que falta autonomia ao Congresso para regulamentar a matéria conforme realizado através da VAWA.

Por mais que Brzonkala tivesse sofrido um grave episódio de abuso sexual, a Suprema Corte se posicionou, em uma polêmica decisão, confirmando a inconstitucionalidade dos remédios civis por ela intentados, estabelecendo que sua proteção deveria ter sido garantida

[...] 'Second, Congress is empowered to regulate and protect the instrumentalities of interstate commerce, or persons or things in interstate commerce, even though the threat may come only from intrastate activities.' [...] 'Finally, Congress' commerce authority includes the power to regulate those activities having a substantial relation to interstate commerce,... i.e., those activities that substantially affect interstate commerce.' [...]”. Cf. United States vs. Morrison, 529 U.S. 598, p. 8-9 (2000) - opinião da Corte. No próprio precedente que fundou a era moderna da cláusula - Jonas \& Laughlin Steel Corp. -, a Corte tratou de impor restrições ao uso da terceira categoria de atividade, o que se reproduziu posteriormente nos casos Lopez e Morrison: "In Jones \& Laughlin Steel, the Court warned that the scope of the interstate commerce power 'must be considered in the light of our dual system of government and may not be extended so as to embrace effects upon interstate commerce so indirect and remote that to embrace them, in view of our complex society, would effectually obliterate the distinction between what is national and what is local and create a completely centralized government'”. Cf. United States vs. Morrison, 529 U.S. 598, p. 7-8 (2000) - opinião da Corte.

20 Cf. United States vs. Lopez, 514 U.S. 549 (1995). O caso será tratado com maior detalhamento a seguir, mas, brevemente, discutia-se sobre a possibilidade de a União regular o porte de arma em zonas escolares. Estudiosos do caso Morrison costumam apontar o caráter vinculante do precedente Lopez em sua decisão: "Morrison solidified many of the principles raised in Lopez. Of prime importance, the Court stressed that the nature of a regulated activity is an essential aspect of the constitutional inquiry. Without adopting a clear rule against the aggregation of individual instances of noneconomic or noncommercial conduct, the Court noted the historical unwillingness to permit this broad use of the commerce power" (CROWELL, 2006, p. 282-283). 
pelo Poder Legislativo do estado da Virgínia, não pelo Congresso dos EUA. ${ }^{21}$ Ironicamente, a Suprema Corte garantiu a autonomia de suas unidades federativas em um precedente que contou com o ingresso de 36 estados, além de Porto Rico, como amici curiae em defesa dos EUA, ou seja, pleiteando a manutenção da validade da norma federal (VAWA) devido a seus efeitos positivos em nível local. ${ }^{22}$ Isso alcançou tanta repercussão no meio acadêmico norte-americano que se comenta ter havido uma garantia da autonomia dos estados, "queiram eles isso ou não" (VIRELLI; LEIBOWITZ, 2001).

Após descrever os fatos que ensejaram a formação do precedente e analisar sua decisão, sobretudo, verificando-se a importância da cláusula de comércio como critério de federalização determinante para a solução da controvérsia, é possível promover um breve paralelo com os poderes constitucionais no Brasil. Dos três precedentes paradigmáticos sobre federalismo nos EUA selecionados, o caso United States vs. Morrison (2000) é o que encontra um comparativo mais superficial e pouco controvertido no Brasil. ${ }^{23}$

Quando os fatos relacionados ao caso Morrison são expostos a fim de se traçar um comparativo com o modelo federativo brasileiro, a primeira relação suscitada parece corresponder ao espectro de proteção legal brasileiro que se convencionou denominar nos últimos anos violência doméstica. Essa é uma matéria, no entanto, que não exprime uma estrita relação com o caso norte-americano, pois, neste, o âmbito de proteção legal pretendido pelo Congresso seria mais amplo. No Brasil, violência doméstica é um assunto que ficou regulamentado

21 Muitos autores consideram essa decisão conservadora, criticando-a por ter causado uma espécie de retrocesso em matéria de proteção de direitos de minorias para fins de preservação do regime federativo do país: "The full impact of the Morrison opinion, both socially and legally, will not become evident for the next several years. On the social level, it is important to remember that, despite the Court's invalidation of section 13981, all the other provisions of the VAWA remain unaffected. Anyone who has not personally been the target of gender-motivated violence cannot fully appreciate the depth of emotional harm suffered by its victims. For past and future victims of gender-motivated violence, the Court's decision is surely a disappointment and represents a backward step in preventing such conduct, possibly in advancing all forms of civil rights" (MARTIN, 2000, p. 332).

22 Além de Porto Rico, os estados que ingressaram com brief as amici curiae foram Arizona, Alaska, Arkansas, California, Colorado, Connecticut, Delaware, Georgia, Hawaii, Illinois, Iowa, Kansas, Kentucky, Louisiana, Maine, Maryland, Minnesota, Mississippi, Missouri, Montana, Nevada, New Hampshire, New Mexico, New York, North Carolina, North Dakota, Oklahoma, Oregon, Rhode Island, Tennessee, Utah, Vermont, Washington, West Virginia and Wisconsin, and the Commonwealths of Massachusetts. Esses estados, inclusive, tentaram comprovar que os índices de violência que antecederam a VAWA geravam elevado custo às administrações locais, mas a tese não foi acatada pela Corte (BANSAL, 2007).

23 Por essa razão, a ordem dos precedentes da Suprema Corte não seguiu uma organização cronológica. Ao contrário, preferiu-se expor os casos de acordo com a complexidade de sua comparação com o cenário normativo brasileiro. Desse modo, o caso United States vs. Lopez (1995), verdadeiro leading case contemporâneo em matéria de federalismo nos EUA, será abordado por último, por permitir maiores discussões ao se confrontar com o contexto brasileiro. 
pela Lei Federal n. 11.340/2006, popularmente conhecida como Lei Maria da Penha. Por definição legal, violência doméstica se restringe a três tipos de relação social: (i) violência cometida em âmbito doméstico; (ii) violência cometida em âmbito familiar; e (iii) violência cometida em âmbito afetivo. ${ }^{24}$ Com rigor, nenhuma das três previsões legais brasileiras são capazes de oferecer especial proteção legal ao abuso sexual sofrido por Brzonkala, vítima de estupro por dois estudantes de sua universidade. Portanto, à exceção da particularidade dos casos integrados à definição legal de violência doméstica, não há no Brasil nenhuma forma especial de proteção legal que combata atos de violência cometidos por motivação de gênero. As únicas formas de proteção contra violência motivada por gênero, assim, são aquelas que ocorrem em âmbito doméstico, familiar ou afetivo, inexistindo regulamentação específica para agressões cometidas por terceiros estranhos a esses núcleos de vínculo social. ${ }^{25}$

Estando a violência motivada por gênero, no Brasil, regulamentada pela disciplina legal genérica do direito penal, não resta muita incerteza quanto ao critério de federalização correspondente. As regras de distribuição de competência legislativa previstas na CRFB/88 são expressas e taxativas ao indicarem que toda matéria que versar sobre direito penal está atribuída à União Federal. ${ }^{26}$ Também os casos de reparação civil do dano decorrente de crime seriam solucionados pela mesma via, uma vez que a competência privativa para legislar em matéria de direito civil se atribuiu à União Federal. Qualquer discussão relacionada ao impacto substantivo dessas práticas no comércio interestadual é absolutamente impertinente para solucionar um conflito federativo no Brasil, pois há outros critérios de federalização mais abrangentes a ser utilizados no país.

24 De acordo com a Lei Federal n. 11.340/2006: "Art. 5 Para os efeitos desta Lei, configura violência doméstica e familiar contra a mulher qualquer ação ou omissão baseada no gênero que lhe cause morte, lesão, sofrimento físico, sexual ou psicológico e dano moral ou patrimonial: I - no âmbito da unidade doméstica, compreendida como o espaço de convívio permanente de pessoas, com ou sem vínculo familiar, inclusive as esporadicamente agregadas; II - no âmbito da família, compreendida como a comunidade formada por indivíduos que são ou se consideram aparentados, unidos por laços naturais, por afinidade ou por vontade expressa; III - em qualquer relação íntima de afeto, na qual o agressor conviva ou tenha convivido com a ofendida, independentemente de coabitação. [...]” (grifos nossos).

25 As agressões sofridas por Brzonkala, no Brasil, são tratadas genericamente pela disciplina de crimes cometidos contra a dignidade sexual, prevista no Código Penal: "Estupro Art. 213. Constranger alguém, mediante violência ou grave ameaça, a ter conjunção carnal ou a praticar ou permitir que com ele se pratique outro ato libidinoso: Pena - reclusão, de 6 (seis) a 10 (dez) anos [...]”. Corroborando o entendimento de que faltam regramentos destinados à proteção contra atos de violência de gênero no Brasil, ver Costa (2014).

26 De acordo com a CRFB/88: “Art. 22. Compete privativamente à União legislar sobre: I - direito civil, comercial, penal, processual, eleitoral, agrário, marítimo, aeronáutico, espacial e do trabalho; [...]” (grifo nosso). 


\section{Uso medicinal da maconha (GoNZALES VS. RAICH)}

No caso Gonzales vs. Raich (2005), a Suprema Corte norte-americana foi provocada a se pronunciar acerca da possibilidade de uso medicinal da maconha. A controvérsia foi iniciada devido à aprovação de uma lei estadual na Califórnia denominada Compassionate Use Act of 1996, permitindo que pacientes com grave quadro clínico residentes em seu território pudessem ter acesso à maconha para propósitos medicinais. Tentava-se, inclusive, com essa medida, encorajar a União e outros estados a liberar o uso medicinal da maconha. ${ }^{27}$ De acordo com o sistema penal norte-americano, a lei estadual previa uma exceção à persecução penal de médicos, pacientes e fornecedores primários, definidos como as pessoas que assumem consistentemente a responsabilidade por estadia, saúde e segurança do paciente, encarregados do uso medicinal da maconha.

Angel Raich e Diane Monson, residentes na Califórnia, encontravam-se em grave quadro clínico, e seus médicos concluíram que o uso terapêutico da maconha era o único método capaz de aliviar seus severos sintomas. Raich e Monson obtiveram licença para iniciar essa terapia e, durante anos, seguiram a recomendação de seus médicos. O problema é que a norma estadual entrou em conflito com uma norma federal que proíbe cultivo, posse ou uso desse tipo de substância, Controlled Substances Act (CSA). ${ }^{28}$ Com base no CSA, agentes federais do Drug Enforcement Administration (DEA) foram à residência de Monson e, embora compreendessem seu uso como legal nos termos da lei estadual, resolveram destruir as plantas encontradas no local. Devido a esse incidente, Raich e Monson ajuizaram uma ação injuntiva e declaratória em face do Attorney General dos EUA - figura semelhante ao advogado-geral da União no Brasil - e do chefe do DEA. O pedido de Raich e Monson se fundava na alegação de que o uso medicinal da maconha com base na lei estadual da Califórnia alcançava impacto meramente intraestadual e, portanto, a aplicação da norma federal a seus casos violaria a cláusula de comércio. A Corte Distrital negou o pedido, alegando que, por mais que negar o acesso a tais meios medicinais pudesse prejudicar os residentes da Califórnia, nenhuma prova teria sido gerada quanto à eficiência da terapia realizada pelos demandantes. Essa decisão, no entanto, foi alterada pela Corte de Apelação correspondente, alegando-se que restaria comprovado o sucesso do procedimento terapêutico. Além desse argumento, a Corte de Apelação entendeu que a norma federal - CSA - violava a cláusula

27 'The proposition was designed to ensure that 'seriously ill' residents of the State have access to marijuana for medical purposes, and to encourage Federal and State Governments to take steps towards ensuring the safe and affordable distribution of the drug to patients in need." Cf. Gonzales vs. Raich, 545 U.S. 1, p. 5-6 (2005) - opinião da Corte.

28 O Congresso dos EUA aprovou a Comprehensive Drug Abuse Prevention and Control Act of 1970 durante o governo de Richard Nixon e sua "guerra contra as drogas", atualmente em vigência. Uma de suas extensas consolidações normativas, o Título II, que regulamenta o controle de substâncias, corresponde à denominada CSA. 
de comércio, uma vez que o uso medicinal da maconha no estado da Califórnia seria simplesmente local e não possuiria natureza de atividade econômica. Inconformado com a reforma da decisão, Alberto Gonzales, Attorney General dos EUA, levou a controvérsia à Suprema Corte norte-americana a fim de comprovar a compatibilidade do CSA com os limites de autoridade do Congresso em regular o comércio interestadual.

Ao enfrentar a controvérsia, a maioria de 6-3 da Suprema Corte norte-americana sustentou que "a autoridade da cláusula de comércio do Congresso inclui o poder de proibir uso e cultivo locais da maconha". ${ }^{29}$ A opinião da Corte foi liderada pelo ilustre representante dos democratas na Corte, Justice John Paul Stevens, seguido pelos demais democratas David Souter, Ruth Ginsburg e Stephen Breyer. Nesse precedente, o swing vote Anthony Kennedy acompanhou o entendimento dos democratas, porém, o mais curioso é que, compondo essa maioria, o republicano Antonin Scalia ofereceu uma opinião concorrente. Embora discordasse dos fundamentos, Scalia votou com a maioria de Justices usualmente reputados como progressistas. ${ }^{30} \mathrm{~A}$ opinião majoritária da Corte reconheceu a autoridade do Congresso para proibir uso e cultivo locais da maconha com base no parâmetro, novamente, da cláusula de comércio. Embora o resultado tenha sido diverso dos encontrados nos precedentes Lopez e Morrison, pois estes negaram autoridade do Congresso, o mesmo critério de federalização foi aplicado na análise da controvérsia. Dessa maneira, foi reforçado o uso da cláusula de comércio como parâmetro normativo de apuração dos limites de autoridade legislativa da União nos EUA na atividade jurisdicional. Raich e Monson não atingiram seu objetivo de afastar uma particular aplicação de uma norma federal válida ao se fundarem no sentido

29 'Held: Congress' Commerce Clause authority includes the power to prohibit the local cultivation and use of marijuana in compliance with California law." (grifo no original). Cf. Gonzales vs. Raich, 545 U.S. 1, p. 1 (2005) - Syllabus.

30 Alguns autores formulam hipóteses para tentar esclarecer porque, surpreendentemente, Kennedy e Scalia acompanharam a vertente progressista da Corte no julgamento de Gonzales vs. Raich - Kennedy pelo fato de constantemente seguir o entendimento de Rehnquist e Scalia por, ao lado de Thomas, ser reputado como radicalmente conservador. Três possíveis motivações são oferecidas. Primeiramente, o caso Raich trata de drogas, assunto que costuma ser alegado como uma excepcionalidade na Corte. Na sequência, negar autoridade ao Congresso para controlar substâncias entorpecentes poderia comprometer o caráter vinculante do precedente Wickard vs. Filburg (gerando overrule). Por fim, Kennedy e Scalia seriam menos comprometidos com o valor do federalismo do que Rehnquist, O'Connor e Thomas (BALMAN, 2005). Acerca da opinião concorrente de Scalia, baseado em fundamento diverso, qual seja, a aplicação da necessary and proper clause: "Justice Scalia's interpretation of the Commerce Clause in Raich reflects a recognized need to defer to congressional policy determinations unless the regulation uses an enumerated power as a pretext to enact unconstitutional legislation. Through the exercise of this sort of limited judicial scrutiny, Justice Scalia's focus on the Necessary and Proper Clause leads to the same result as Justice Stevens, without the slippery attempts to reconcile the Controlled Substances Act's ban on all marijuana with the doctrine forged in Lopez and Morrison" (CROWELL, 2006, p. 319-320). 
original da cláusula de comércio. ${ }^{31}$

O complexo controle exercido pela CSA agrupa substâncias segundo critérios como os efeitos psicológicos e fisiológicos produzidos no organismo como forma de instituir diferentes níveis de rigor de sua produção, distribuição e uso. A maconha se encontra no primeiro grupo de substâncias (Schedule I), reunidos devido ao "elevado potencial de dependência, ausência de qualquer uso medicinal admitido e ausência de qualquer nível aceitável de segurança para seu uso terapêutico supervisionado”. ${ }^{32}$ É nessa classificação, especificamente, que o conflito entre as normas estadual e federal se torna mais claro e preciso. Os diferentes agrupamentos previstos na CSA podem ser constantemente atualizados ou modificados por iniciativa do Attorney General, após consultar a Secretaria de Saúde e de Serviços Humanos (Secretary of Health and Human Services), o que reforça o argumento de que os órgãos federais poderiam transferir a maconha para grupos cujo controle menos rigoroso autorizasse seu uso terapêutico se convencidos de que há razões suficientes.

O fundamento decisório adotado pelo Justice Stevens na opinião que liderou a maioria da Corte foi o mesmo encontrado na decisão de United States vs. Morrison (2000): a cláusula

31 A decisão do caso a partir do sentido original da cláusula de comércio poderia ter conduzido o precedente a resultado diverso, pois, no momento inaugural, esse poder do Congresso era mais limitado, não contando com a extensão promovida por sua era moderna - impacto substantivo no comércio interestadual mesmo em ações não comerciais e locais. Randy Barnett promoveu investigações de natureza histórica a fim de revelar qual seria o sentido original da cláusula de comércio, tendo concluído o seguinte: "Commerce' means the trade or exchange of goods (including the means of transporting them); 'among the several States' means between persons of one state and another; and the term 'To regulate' means 'to make regular' - that is, to specify how an activity may be transacted - when applied to domestic commerce, but also includes the power to make 'prohibitory regulations' when applied to foreign trade. In sum, Congress has power to specify rules to govern the manner by which people may exchange or trade goods from one state to another, to remove obstructions to domestic trade erected by states, and to both regulate and restrict the flow of goods to and from other nations (and the Indian tribes) for the purpose of promoting the domestic economy and foreign trade" (BARNETT, 2001, p. 146). Barnett possuía uma motivação muito pessoal para perseguir esse sentido original: ele foi o patrono de Angel Raich e Diane Monson, réus de Gonzales vs. Raich. Após sua tese não prevalecer na Corte, Barnett passou a defender a necessidade de limitar o uso do caso Raich como precedente vinculante em matéria de federalismo, sustentando esse posicionamento quase como se elaborasse um manifesto (BARNETT, 2005).

32 "Schedule I drugs are categorized as such because of their high potential for abuse, lack of any accepted medical use, and absence of any accepted safety for use in medically supervised treatment. [...] These three factors, in varying gradations, are also used to categorize drugs in the other four schedules. For example, Schedule II substances also have a high potential for abuse which may lead to severe psychological or physical dependence, but unlike Schedule I drugs, they have a currently accepted medical use. [...] By classifying marijuana as a Schedule I drug, as opposed to listing it on a lesser schedule, the manufacture, distribution, or possession of marijuana became a criminal offense, with the sole exception being use of the drug as part of a Food and Drug Administration pre-approved research study." (grifo nosso). Cf. Gonzales vs. Raich, 545 U.S. 1, p. 14 (2005) opinião da Corte. 
de comércio. De modo muito similar a este último precedente, Stevens discriminou as três categorias de aplicação dessa cláusula, ressaltando sua expansão na era moderna a partir do caso NLRB vs. Jones \&Laughlin Steel Corp. (1937) com o critério do substancial impacto no comércio interestadual - determinante para a solução dessa controvérsia. ${ }^{33}$ Reforçando seu entendimento, Stevens aponta um precedente em que a cláusula de comércio foi utilizada como critério de federalização: Wickard vs. Filburn (1942). ${ }^{34}$

Nesse precedente, Roscoe Filburn, um pequeno fazendeiro, alegou inconstitucionalidade da Agricultural Adjustment Act of 1938, que controlava o mercado agrícola a partir do volume da produção. Filburn produziu um volume de cevada superior ao permitido, mas alegou que o excedente se destinava ao consumo interno da própria fazenda, não sendo revertido ao mercado. Com isso, sob a alegação de que sua produção era local e de que seus atos não possuíam natureza econômica, suscitou a inconstitucionalidade da lei por ausência de autoridade do Congresso para regular a matéria. A Suprema Corte rejeitou tais argumentos, defendendo que, mesmo se destinando ao consumo próprio da fazenda, Filburn interferiu nas relações de oferta e procura, pois se comprasse o que não poderia produzir para atender a seu consumo, aumentaria a demanda no mercado. Com isso, aplicou-se o parâmetro da cláusula de comércio, indicando que, mesmo sendo uma questão local e que não representa atividade econômica, os fatos causaram impacto substantivo no comércio interestadual de

33 Cf. NLRB vs. Jones \& Laughlin Steel Corp., 301 U.S. 1 (1937). A análise realizada em Raich a partir dos corolários da cláusula de comércio indicados acima encontra certa resistência em alguns pesquisadores críticos a esse precedente: "In any given intrastate case, the Court may use one or more of the following interpretations of the express language in the Commerce Clause: (1) Interstate Paradox: Even though the Commerce Clause authorizes Congress to regulate commerce among the states - interstate commerce - Congress can regulate intrastate commerce - commerce that is confined to, or occurs within, a single state. 'Interstate' means 'intrastate.' (2) Commerce Paradox: Even though the Commerce Clause authorizes Congress to regulate commerce, the commerce power extends to noncommercial, noneconomic activities. The commerce power is about power, not commerce. The commerce power is a plenary, national 'police power.' (3) Substantial Paradox: Even though cases hold that intrastate conduct that has a substantial effect on interstate commerce can be regulated, Congress can regulate conduct with a trivial and inconsequential effect on interstate commerce. 'Substantial' means 'trivial.' [...] A question immediately arises: Is constitutional irony good or bad? [...] Raich involved all three Commerce Clause paradoxes. The thesis of this article is that constitutional irony is bad - very bad" (BALMAN, 2005, p. 126-127).

34 Cf. Wickard v. Filburn, 317 U.S. 111 (1942). Citando este mencionado precedente: "As we stated in Wickard, 'even if appellee's activity be local and though it may not be regarded as commerce, it may still, whatever its nature, be reached by Congress if it exerts a substantial economic effect on interstate commerce."” Cf. Gonzales vs. Raich, 545 U.S. 1 (2005) - opinião da Corte. Apesar do caráter vinculante do precedente Wickard, um apontamento de natureza histórica se mostra necessário: esse caso foi decidido pelos Roosevelt Justices, durante o conturbado período do New Deal, caracterizado por uma significativa centralização e, inclusive, pelo exercício de uma forte pressão política sobre a Suprema Corte para que esta admitisse maior intervenção na economia por parte da presidência (BALMAN, 2005). 
cevada. Assim como em Wickard, a Corte asseverou em Raich que condutas locais sem natureza econômica podem estar inseridas na autoridade do Congresso se houver substantivo impacto sobre o comércio interestadual. Desse modo, o fato de Raich e Monson cultivarem maconha para consumo próprio visando finalidade medicinal, por mais que representasse uma prática local e sem natureza de atividade econômica, subvertia a regulação do controle de oferta e demanda no mercado químico e farmacológico - mesmo aqueles ilegais -, gerando, portanto, um substancial impacto no comércio interestadual. ${ }^{35}$ Como resultado, portanto, a Suprema Corte confirmou a autoridade do Congresso para legislar em matéria de uso medicinal da maconha, impossibilitando que o estado da Califórnia pudesse legitimamente autorizar essa prática.

Uma vez apresentado outro paradigmático caso norte-americano, pode-se compará-lo com o tratamento legal que a matéria eventualmente teria recebido no Brasil. Em resumo, o ordenamento jurídico brasileiro não oferece saídas muito distintas das encontradas ao se analisar o caso Morrison. O critério de federalização correspondente à matéria, que se encontra dentro do direito material penal, é a competência formal para legislar que foi atribuída pela CRFB/ 88 à União Federal. ${ }^{36}$ Portanto, assim como o primeiro caso, não há grandes mistérios acerca de como a questão de uso e cultivo da maconha para fins terapêuticos seria abordada no Brasil no plano federativo.

O uso e o cultivo de maconha, no país, é crime, embora as condutas típicas possam estar dispostas em regramentos legais diversos na Lei Federal n. 11.343/2006. Inicialmente, cultivar maconha para fins comerciais se adequaria tipicamente à conduta descrita no art. 33 da Nova Lei de Tóxicos, que prevê o crime de tráfico. ${ }^{37}$ No entanto, o fato de haver cultivo

35 "Wickard thus establishes that Congress can regulate purely intrastate activity that is not itself "commercial,' in that it is not produced for sale, if it concludes that failure to regulate that class of activity would undercut the regulation of the interstate market in that commodity. The similarities between this case and Wickard are striking. Like the farmer in Wickard, respondents are cultivating, for home consumption, a fungible commodity for which there is an established, albeit illegal, interstate market. Just as the Agricultural Adjustment Act was designed 'to control the volume [of wheat] moving in interstate and foreign commerce in order to avoid surpluses ...' and consequently control the market price, [...] a primary purpose of the CSA is to control the supply and demand of controlled substances in both lawful and unlawful drug markets." Cf. Gonzales vs. Raich, 545 U.S. 1, p. 18-19 (2005) - opinião da Corte. Importante ressaltar que, ao final desse trecho, a Corte aponta que o substantivo impacto no comércio interestadual considerado na decisão não faz distinção entre mercados lícitos e ilícitos. Ambos foram considerados durante a aplicação da cláusula de comércio para decidir a controvérsia acerca do uso terapêutico da maconha.

36 De acordo com o art. 22, I, da CRFB/88: “Art. 22. Compete privativamente à União legislar sobre: I - direito civil, comercial, penal, processual, eleitoral, agrário, marítimo, aeronáutico, espacial e do trabalho; [...]" (grifo nosso).

37 O crime de tráfico, pelo fato de prever um número muito extenso de condutas capazes de tipificá-lo, é classificado pela doutrina como um crime de ação múltipla, ou misto alternativo. Entre tais condutas, há o 
para uso próprio remete para outro enunciado normativo-incriminador, o art. 28, parágrafo único, que promove equiparação à situação jurídica do usuário. ${ }^{38} \mathrm{Na}$ hipótese de surgimento de uma norma legal autorizando cultivo, distribuição e uso da maconha para fins terapêuticos no Brasil, essa previsão corresponderia tecnicamente a uma causa legal de exclusão da ilicitude das condutas mencionadas acima. No direito penal brasileiro, entende-se que o conceito analítico de crime pressupõe a observância de um fato típico, ilícito e culpável. O fato típico, na tradicional teoria finalística do crime, depende da constatação de elementos como a conduta humana, comissiva ou omissiva, a tipicidade formal e penalmente relevante dessa conduta, a produção de um resultado previsto no tipo e o nexo de causalidade entre a conduta perpetrada e o resultado produzido. A partir do momento que se comprova a existência de um fato típico, presume-se que esse fato ofende o direito. Portanto, a avaliação da ilicitude do fato típico se resume à identificação de hipóteses legais que afastam o caráter antijurídico do ocorrido. Entre as mais recorrentes causas excludentes de ilicitude, há a legítima defesa, o estado de necessidade e o estrito cumprimento de dever legal, havendo outras causas menos convencionais como o consentimento do ofendido - causa supralegal que exclui a ilicitude do fato típico.

O controle de substâncias exercido nos EUA, pela CSA pode ser comparado com a atribuição que possui o Ministério da Saúde no Brasil, por meio de sua Secretaria de Vigilância Sanitária. A doutrina penal, ao se dedicar ao crime de tráfico, costuma tratá-lo como norma penal em branco, devido à incompletude do sentido do preceito primário de seu dispositivo legal ao mencionar "drogas [...] sem autorização ou em desacordo com determinação legal

cultivo. De acordo com a Lei Federal n. 11.343/2006: "Art. 33. Importar, exportar, remeter, preparar, produzir, fabricar, adquirir, vender, expor à venda, oferecer, ter em depósito, transportar, trazer consigo, guardar, prescrever, ministrar, entregar a consumo ou fornecer drogas, ainda que gratuitamente, sem autorização ou em desacordo com determinação legal ou regulamentar: Pena - reclusão de 5 (cinco) a 15 (quinze) anos e pagamento de 500 (quinhentos) a 1.500 (mil e quinhentos) dias-multa. $\S 1^{\circ}$ Nas mesmas penas incorre quem: I - importa, exporta, remete, produz, fabrica, adquire, vende, expõe à venda, oferece, fornece, tem em depósito, transporta, traz consigo ou guarda, ainda que gratuitamente, sem autorização ou em desacordo com determinação legal ou regulamentar, matéria-prima, insumo ou produto químico destinado à preparação de drogas; II - semeia, cultiva ou faz a colheita, sem autorização ou em desacordo com determinação legal ou regulamentar, de plantas que se constituam em matéria-prima para a preparação de drogas; III - utiliza local ou bem de qualquer natureza de que tem a propriedade, posse, administração, guarda ou vigilância, ou consente que outrem dele se utilize, ainda que gratuitamente, sem autorização ou em desacordo com determinação legal ou regulamentar, para o tráfico ilícito de drogas [...]” (grifo nosso).

38 De acordo com a Lei Federal n. 11.343/2006: "Art. 28. Quem adquirir, guardar, tiver em depósito, transportar ou trouxer consigo, para consumo pessoal, drogas sem autorização ou em desacordo com determinação legal ou regulamentar será submetido às seguintes penas: [...] $\S 1^{\circ}$ Às mesmas medidas submete-se quem, para seu consumo pessoal, semeia, cultiva ou colhe plantas destinadas à preparação de pequena quantidade de substância ou produto capaz de causar dependência física ou psíquica [...]” (grifos nossos). 
ou regulamentar". O que promove a integração de sentido de tais termos é a Portaria da Secretaria de Vigilância Sanitária do Ministério da Saúde n. 344/1998, que define quais são as substâncias controladas e dispõe sobre as condições de autorização para praticar qualquer dos atos descritos em seu art. $2^{\circ} .^{39}$

A maconha, para todos os fins legais, é classificada como substância psicotrópica no Brasil. ${ }^{40} \mathrm{O}$ uso e o cultivo de maconha para fins medicinais, portanto, dependeria de expressa previsão das autoridades federais, mas o critério de federalização responsável por centralizar a matéria no país é, simplesmente, genérico, baseado em uma disciplina jurídica, não havendo qualquer análise minuciosa das razões dessa federalização. Enquanto a Suprema Corte norte-americana discutia arduamente acerca da possibilidade de os estados regularem a matéria, analisando os limites da autoridade do Congresso norte-americano para legislar sobre o controle de substâncias no país a partir da cláusula de comércio, o que define a questão, no Brasil, é um critério absolutamente formal e abrangente: compete privativamente à União legislar sobre direito penal. Nenhum tipo de reflexão mais aprofundada é permitida havendo um critério generalizador como este.

\section{Porte de arma em zona escolar (United States vs. Lopez)}

No caso United States vs. Lopez (1995), a Suprema Corte norte-americana foi provocada a se pronunciar em uma controvérsia acerca do porte de arma em zona escolar. ${ }^{41}$ Os fatos se desdobraram no estado do Texas, onde um estudante de ensino médio, Alfonso Lopez Jr., adentrou as instalações de sua escola, Edison High School, portando um revólver, calibre 38, municiado com cinco projéteis. Após uma denúncia anônima, as autoridades da escola verificaram a ocorrência e, como resultado, Lopez foi reprimido pelas normas internas da escola e também pela lei penal do estado do Texas. No dia seguinte, todavia, as acusações estaduais contra Lopez foram retiradas, pois autoridades federais arguiram violação a uma norma situada em sua esfera de atuação.

39 De acordo com a Portaria da Secretaria de Vigilância Sanitária do Ministério da Saúde n. 344/1998: “Art. $2^{\circ}$ Para extrair, produzir, fabricar, beneficiar, distribuir, transportar, preparar, manipular, fracionar, importar, exportar, transformar, embalar, reembalar, para qualquer fim, as substâncias constantes das listas deste Regulamento Técnico (ANEXO I) e de suas atualizações, ou os medicamentos que as contenham, é obrigatória a obtenção de Autorização Especial concedida pela Secretaria de Vigilância Sanitária do Ministério da Saúde”.

40 De acordo com a Portaria da Secretaria de Vigilância Sanitária do Ministério da Saúde n. 344/1998: “LISTA F2 - SUBSTÂNCIAS PSICOTRÓPICAS [...] 28. THC (TETRAIDROCANABINOL)”.

41 Cf. United States vs. Lopez, 514 U.S. 549 (1995). Para fins de definição, a legislação federal definiu "zona escolar” como o interior, bem como suas dependências, de uma escola pública, paroquial ou privada, também considerando como tal uma distância de mil pés (aproximadamente 305 metros) das dependências de uma escola pública, paroquial ou privada. 
A lei que se alegava ter sido violada era a Gun-Free School Zones Act of 1990 (GFSZ), que descreve como crime o fato de "qualquer indivíduo consciente de portar arma de fogo estar em local que saiba ser, ou que tenha causa razoável para suspeitar que seja, uma zona escolar". ${ }^{42}$ As acusações na Corte Distrital foram julgadas procedentes e o veredito proferido contra Lopes previa uma penalidade de seis meses de encarceramento, além de um período de mais dois anos sob livramento supervisionado, semelhante ao regime do livramento condicional observado no processo penal brasileiro. A condenação de Lopez não foi mantida pela Corte de Apelação, que reformou a decisão anterior por entender que o Congresso excedeu seus poderes constitucionais de regular o comércio. Novamente, é indispensável notar que a cláusula de comércio foi selecionada como critério determinante para a avaliação de ocorrência de federalização da controvérsia.

As deliberações travadas no interior da Suprema Corte norte-americana conduziram a um quadro dividido no enfrentamento do caso United States vs. Lopez (1995). De maneira geral, o precedente teve como resultado, por 5-4, a confirmação de que o Congresso excedeu sua autoridade em regular o comércio ao definir como crime a prática do porte de arma de fogo em zona escolar. Ao aprofundar as observações quanto ao resultado do julgamento, o quadro se agrava. Entre os cinco Justices que votaram pela inconstitucionalidade da GFSZ, a opinião predominante na Corte foi a oferecida pelo Chief Justice William Rehnquist, seguido pelos Justices mais conservadores - Antonin Scalia e Clarence Thomas - e pelos compreendidos por estudiosos da Suprema Corte como swing votes - Anthony Kennedy e Sandra O'Connor. No entanto, Kennedy ofereceu uma opinião concorrente à de Rehnquist, embora com ele concordasse e no mesmo sentido votasse, expondo fundamentação adicional, a que somente O'Connor aderiu. No lado dissidente da Corte, encontram-se aqueles Justices considerados mais progressistas - John Paul Stevens, David Souter, Stephen Breyer e Ruth Ginsburg. Houve divergência, no entanto, entre os próprios vencidos, que ofereceram opiniões dissidentes que concorriam entre si. Entre estes quatro, Stevens, Souter e Breyer lançaram opiniões particulares, tendo somente a de Breyer obtido adesão dos demais dissidentes. Em síntese, prevaleceu o entendimento manifestado pela composição conservadora da Corte, sustentando-se que "[a] Lei excede a autoridade da cláusula de comércio do Congresso", repetindo-se o parâmetro de decisão em matéria de federalismo. ${ }^{43}$

42 "[...] for any individual knowingly to possess a firearm at a place that the individual knows, or has reasonable cause to believe, is a school zone." Cf. United States vs. Lopez, 514 U.S. 549, p. 551 (1995) - opinião da Corte.

43 “Held: The Act exceeds Congress' Commerce Clause authority." (grifo no original). Cf. United States vs. Lopez, 514 U.S. 549, p. 1 (1995) - Syllabus. O caráter conservador dessa decisão é abordado com frequência entre constitucionalistas e cientistas políticos: "The Lopez decision underscored the significant changes wrought by Republican presidentes Ronald Reagan and George H. W. Bush on the Court. The decision was widely viewed at the time as a stalking horse by the Court's conservative justices to attack a wide range of federal social politicies. Perhaps most important, however, the decision affirmed the strong interest of the high court in supporting state sovereignty, a development that has became a hallmark of the Rehnquist Court” (HALL, 2005, p. 593). 
A fundamentação de Rehnquist, em defesa da inconstitucionalidade da lei federal por faltar autoridade ao Congresso, é iniciada com uma retrospectiva histórica da construção semântica da cláusula de comércio. Após indicar aspectos normativos com uma aproximação bem similar a que costuma ser apresentada por originalistas, dialogando com os Founders e seu original intent, alguns casos são citados como precedentes ao caso Lopez, asseverando a necessidade de preservação dos poderes dos estados como forma de controle do governo - em um típico exemplo de tiranofobia. ${ }^{44}$ Entre os precedentes mencionados, Rehnquist destacou o paradigmático caso de NLRB vs. Jonas \& Laughlin Steel Corp. (1937), que inaugurou, na Suprema Corte, a compreensão de que a cláusula de comércio permite que o Congresso regule atividades intraestaduais que causem substantivo impacto no comércio interestadual. ${ }^{45} \mathrm{Tal}$ entendimento foi reforçado no precedente United States vs. Darby (1941), que reconheceu a autoridade do Congresso para uniformizar condições de trabalho no país, durante o sensível e conturbado período da Segunda Grande Guerra, declarando a constitucionalidade da Fair Labor Standards Act of 1938. ${ }^{46}$ Por fim, o caso Wickard vs. Filburg (1942) é novamente abordado, reiterando como os dilemas federativos, a partir de meados do século XX, passaram a ser solucionados basicamente pela

44 A tiranofobia é um fenômeno muito comum nos EUA e é abordado como uma tentativa desnecessária e infundada de limitar o poder de um governo antes que este se torne tirano na obra (POSNER; VERMEULE, 2011). Quando os autores questinam a eficácia dos meios madisonianos de controle do Poder Executivo - rule of law e checks and balances -, passam a abordar o temor norte-americano da tirania. Ausentes essas formas tradicionais de limitação do governo, os defensores do madisonianismo costumam contra-argumentar expressando o medo de formação de um governo autoritário. Na verdade, os madisonianos temem que, sem tais mecanismos de controle, o Executivo fique absolutamente ilimitado - daí o título da obra The Executive Unbound, em tom de crítica a essa corrente de pensamento. Posner e Vermeule sustentam, por sua vez, que existem outros mecanismos - os denominados pós-madisonianos - que são mais eficientes na contenção do Executivo: a credibilidade a ser conquistada perante oficiais do governo e a popularidade do presidente como meio necessário à aprovação de seus planos políticos, o que dispensaria o medo da tirania enquanto forma de controle social da atuação política do presidente.

45 Cf. NLRB vs. Jones \& Laughlin Steel Corp., 301 U.S. 1 (1937). Nesse precedente, julgou-se que a recusa de entidades industriais a participar de negociações coletivas com seus empregados acarretaria substantivos efeitos no comércio interestadual e, assim, foi abandonada a doutrina tradicional de que questões locais e sem natureza diretamente de atividade comercial pudessem integrar a autoridade do Congresso para regular o comércio. De todo modo, relevante pontuar o período histórico de forte centralização política vivenciado pelo país durante o governo de Franklin Roosevelt.

46 "In United States v. Darby, 312 U.S. 100 (1941), the Court upheld the Fair Labor Standards Act, stating: 'The power of Congress over interstate commerce is not confined to the regulation of commerce among the states. It extends to those activities intrastate which so affect interstate commerce or the exercise of the power of Congress over it as to make regulation of them appropriate means to the attainment of a legitimate end, the exercise of the granted power of Congress to regulate interstate commerce'.”. Cf. United States vs. Lopez, 514 U.S. 549, p. 555 (1995) - opinião da Corte. 
interpretação da cláusula de comércio do Congresso e, especialmente, através de seu consectário moderno - o substantivo impacto no comércio interestadual. ${ }^{47} \mathrm{~A}$ conclusão extraída de tais precedentes por Rehnquist é que, mesmo com a expressiva expansão da doutrina da cláusula de comércio na Suprema Corte, acompanhando as mudanças que teriam ocorrido na própria estrutura da economia no país, a autoridade do Congresso para regular o comércio não deve atingir toda forma de atividade comercial intraestadual ou todo impacto no comércio interestadual que não possa ser compreendido como substancial e direto, sob pena de se conduzir a um regime de forte centralização federativa. ${ }^{48}$

A exposição da construção histórica e jurisprudencial do sentido da cláusula de comércio promovida por Rehnquist é seguida por uma espécie de teste à tese confrontada pela Corte. Com isso, enfrenta-se o questionamento principal do caso Lopez - se o Congresso excedeu sua autoridade de regular o comércio ao criminalizar o porte de arma de fogo em zona escolar - submetendo-o, sucessivamente, aos três consectários da era moderna da commerce clause: (i) atividade comercial interestadual, (ii) fator instrumental ao comércio interestadual e (iii) substancial impacto no comércio interestadual. De modo muito breve, as duas primeiras hipóteses são afastadas pela opinião da Corte, passando-se à avaliação do último e determinante consectário desse critério de federalização. ${ }^{49}$ Abordando o terceiro consectário, Rehnquist sustenta que, entre os precedentes da era moderna da cláusula de comércio, existe um padrão que pode ser observado e recorre ao exemplo extremado do

47 Cf. Wickard v. Filburn, 317 U.S. 111 (1942).

48 “Jones \& Laughlin Steel, Darby, and Wickard ushered in an era of Commerce Clause jurisprudence that greatly expanded the previously defined authority of Congress under that Clause. In part, this was a recognition of the great changes that had occurred in the way business was carried on in this country. Enterprises that had once been local or at most regional in nature had become national in scope. But the doctrinal change also reflected a view that earlier Commerce Clause cases artificially had constrained the authority of Congress to regulate interstate commerce." Cf. United States vs. Lopez, 514 U.S. 549, p. 556 (1995) - opinião da Corte.

49 "We now turn to consider the power of Congress, in the light of this framework, to enact $§ 922(q)$. The first two categories of authority may be quickly disposed of: §922(q) is not a regulation of the use of the channels of interstate commerce, nor is it an attempt to prohibit the interstate transportation of a commodity through the channels of commerce; nor can $\$ 922(q)$ be justified as a regulation by which Congress has sought to protect an instrumentality of interstate commerce or a thing in interstate commerce. Thus, if $\S 922(\mathrm{q})$ is to be sustained, it must be under the third category as a regulation of an activity that substantially affects interstate commerce." Cf. United States vs. Lopez, 514 U.S. 549, p. 559 (1995) - opinião da Corte. Os argumentos apresentados pela opinião da Corte receberam algumas críticas de defensores do federalismo nacionalista, a exemplo das seguintes: "Although the Justices can be congratulated for raising a fundamental issue that deserves rethinking, their resoning is profundly unsathisfying. The doctrinal categories of 'noncommercial activities' and 'areas of traditional state regulation' constructed by the majority ressurect the mindless formalism of the Lochner Court. These categories enforce a blindness to the obvious national enonomic consequences of education, Family structure, and tort liability, and otherwise disregard federalism's underlying values" (STACY, 1996, p. 244). 
caso Wickard para argumentar que, em Lopez, esse padrão não se repete. De acordo com o Chief Justice que liderou a orientação da Suprema Corte nesse precedente, um aluno adentrar em sua escola portando uma arma de fogo não alcança qualquer repercussão no plano do comércio interestadual. ${ }^{\mathbf{5 0}}$

Seguindo o exemplo do precedente Morrison, também em Lopez foram suscitados os argumentos de "custos do crime", distribuídos pela população, e de "produtividade nacional”, acerca dos prejuízos econômicos de locais com elevados índices de violência, sobretudo em matéria de turismo. Em nenhum desses casos, prevaleceram tais argumentos arrazoados pelos EUA perante a Suprema Corte. Em resposta, Rehnquist justifica a inexistência de impacto substantivo no comércio interestadual alegando que “[s]ob as teorias [...] é difícil perceber qualquer limitação ao poder federal, mesmo em áreas como direito penal ou educação, onde o estado historicamente tem sido soberano". 51 O Justice Breyer, em sua opinião dissidente, defende que a questão do porte de arma em zona escolar estaria abrangida pela autoridade do Congresso ao regular o comércio devido a seu impacto sobre o aprendizado. Para Breyer, a presença de arma de fogo nessas regiões, em primeiro lugar, gera insegurança. Em segundo, isso pode prejudicar o aprendizado dos estudantes e, enfim, o comprometimento da formação escolar acarretaria sérios problemas ao comércio. ${ }^{52}$ Essa não foi, porém, a opinião que conquistou a maioria dos julgadores, tendo sido mais bem recebido o argumento de Rehnquist de que o poder do Congresso, a despeito de sua preocupação com a segurança dos estudantes, "não inclui a autoridade para regular todo e qualquer aspecto de escolas locais" e que, para estabelecer um nexo entre o porte de arma em zona escolar e o comércio interestadual, "teríamos que empilhar inferências sobre inferências de uma maneira que seria justo converter a autoridade do Congresso [...] em um poder geral de polícia”. ${ }^{\mathbf{5 3}}$

50 "Even Wickard, which is perhaps the most far reaching example of Commerce Clause authority over intrastate activity, involved economic activity in a way that the possession of a gun in a school zone does not." Cf. United States vs. Lopez, 514 U.S. 549, p. 560 (1995) - opinião da Corte.

51 "Under the theories that the Government presents in support of $\S 922(q)$, it is difficult to perceive any limitation on federal power, even in areas such as criminal law enforcement or education where States historically have been sovereign.” Cf. United States vs. Lopez, 514 U.S. 549, p. 564 (1995) - opinião da Corte.

52 "Justice Breyer focuses, for the most part, on the threat that firearm possession in and near schools poses to the educational process and the potential economic consequences flowing from that threat. [...] Specifically, the dissent reasons that (1) gun related violence is a serious problem; (2) that problem, in turn, has an adverse effect on classroom learning; and (3) that adverse effect on classroom learning, in turn, represents a substantial threat to trade and commerce.” Cf. United States vs. Lopez, 514 U.S. 549, p. 565 (1995) opinião da Corte.

53 "That authority, though broad, does not include the authority to regulate each and every aspect of local schools. [...] To uphold the Government's contentions here, we would have to pile inference upon inference in a manner that would bid fair to convert congressional authority under the Commerce Clause to a 
Diante do tratamento constantemente oferecido pela Suprema Corte norte-americana às questões federativas que lhe são lançadas, tendo, em mais uma oportunidade, a cláusula de comércio se mostrado como critério determinante de federalização no país, é possível traçar um comparativo com o cenário brasileiro. Dos três assuntos abordados neste artigo, este é o que oferece maior desafio à estrutura federativa brasileira. Embora o caso pareça se esgotar com a mesma discussão encontrada nas temáticas acima - violência motivada por gênero e uso terapêutico da maconha -, simplesmente se recorrendo ao art. 22, I, da CRFB/88, alguns avanços podem ser considerados.

Se a abordagem da controvérsia do porte de arma de fogo em zona escolar não fosse tratado especificamente sob o ponto de vista criminal, apenas se estabelecendo uma proibição com caráter administrativo, o desfecho da questão poderia ser diverso. ${ }^{\mathbf{5 4}}$ Tal abordagem conduziria a um quadro menos simples de enfrentamento. Em princípio, porte de arma - a despeito da conotação penal do caso - é um assunto que não se encontra elencado nos róis numerus clausus de competências da União Federal ou dos municípios - bem como a matéria de segurança pública. Desse modo, prevalece a regra do sistema federativo de que as competências não enumeradas presumem-se insertas na autoridade dos

general police power of the sort retained by the States." Cf. United States vs. Lopez, 514 U.S. 549, p. 566-567 (1995) - opinião da Corte.

54 Avaliando-se o contexto legal brasileiro, uma importante distinção terminológica deve ser promovida entre porte e posse de arma de fogo sob o marco da Lei Federal n. 10.826/2003, difundido como Estatuto do Desarmamento. Inicialmente, há uma distinção entre armas de fogo de uso proibido ou restrito e armas de fogo de uso permitido, que, no entanto, precisam se submeter a regras legais e regulamentares para que não se mantenha a licitude de seu porte ou posse. Quanto às armas de fogo de uso permitido, portanto, a posse qualifica a manutenção de sua guarda (i) no interior ou às dependências da residência ou (ii) em seu local de trabalho. Os atos penalmente relevantes que, por exclusão, não configuram a posse de arma de fogo são tratados como casos de porte. Com isso, o plano fático por trás do precedente de Lopez mais se adequaria, ao se comparar com o contexto legal brasileiro, com a prática do porte de arma de fogo do que com a de posse. Nada impede que a proibição alcance eventuais agentes de segurança que trabalham em zona escolar - ou mesmo profissionais que residem em dependências da escola, como é comum em entidades religiosas de ensino -, mas o sentido ambicionado pela norma federal seria o de impedir o que se entende ser porte de arma de fogo no Brasil. De acordo com a Lei Federal n. 10.826/2003: "Posse irregular de arma de fogo de uso permitido Art. 12. Possuir ou manter sob sua guarda arma de fogo, acessório ou munição, de uso permitido, em desacordo com determinação legal ou regulamentar, no interior de sua residência ou dependência desta, ou, ainda no seu local de trabalho, desde que seja o titular ou o responsável legal do estabelecimento ou empresa: Pena detenção, de 1 (um) a 3 (três) anos, e multa. [...] Porte ilegal de arma de fogo de uso permitido Art. 14. Portar, deter, adquirir, fornecer, receber, ter em depósito, transportar, ceder, ainda que gratuitamente, emprestar, remeter, empregar, manter sob guarda ou ocultar arma de fogo, acessório ou munição, de uso permitido, sem autorização e em desacordo com determinação legal ou regulamentar: Pena reclusão, de 2 (dois) a 4 (quatro) anos, e multa. Parágrafo único. O crime previsto neste artigo é inafiançável, salvo quando a arma de fogo estiver registrada em nome do agente”. 
estados. ${ }^{\mathbf{5 5}}$ Esse seria um raciocínio adequado do ponto de vista federativo, mas porte de arma de fogo, no Brasil, ainda assim, parece ser caso de centralização política.

O porte de arma de fogo, no país, recentemente observou a instauração de um marco legal de regulação federal: a Lei Federal n. 10.826/2003, popularizada como Estatuto do Desarmamento. Embora o regime de distribuição formal de competências disposto na CRFB/88 não elenque porte de arma de fogo ou segurança pública como atribuição da União Federal, o Estatuto do Desarmamento, atualmente em vigor, foi aprovado pelo Congresso Nacional e referendado pela população. O caso ensejou o ajuizamento de uma Ação Direta de Inconstitucionalidade (ADI) no Supremo Tribunal Federal, alegando, entre outras inconformidades, inconstitucionalidade formal da norma federal por regulamentar uma matéria de competência dos estados. ${ }^{\mathbf{5 6}}$

A despeito de qualquer estudioso do tema federalismo compreender o caso como uma patente e explícita violação ao regime de distribuição de competências legislativas, prevaleceu o entendimento na Corte de que não houve invasão da competência residual dos estados. Ficou estabelecido, no acórdão da decisão do Supremo Tribunal Federal, a constitucionalidade da norma federal "pois cabe à União legislar sobre matérias de predominante interesse geral”. Na doutrina tradicional do direito constitucional, é possível encontrar recorrentes remissões à denominada "teoria da predominância do interesse", definindo se a questão enfrentada deveria ser regulamentada pela esfera federal, estadual ou municipal. Esta é uma teoria, no entanto, destinada propriamente a solucionar conflitos de competência legislativa concorrente e administrativa comum, exclusivamente para aquelas disposições elencadas nos arts. 23 e 24 da CRFB/88. Quando a competência legislativa é privativa, somente se admite a delegação parcial nos termos do art. 22, parágrafo único, da CRFB/88, por meio de lei complementar, não existindo em nosso regime federativo previsão que autorize a avocação de competência privativa do estado pela União Federal a despeito de suposto "predomínio de interesse geral”. ${ }^{\mathbf{5 7}}$ Diante dessa surpreendente decisão, a única conclusão plausível a que se pode chegar é que não bastam os critérios fortemente centralizadores previstos em nossa forma de federalismo formal.

Mesmo nos casos em que a controvérsia, ao menos ratione materiae, não indica que o caso esteja atribuído à autoridade da União Federal no Brasil, encontra-se um modo formal de centralização. Afastar o critério relativo à matéria, enquanto meio de centralização, não

55 De acordo com a CRFB/88: "Art. 25. Os Estados organizam-se e regem-se pelas Constituições e leis que adotarem, observados os princípios desta Constituição. $\S 1^{\circ}$ - São reservadas aos Estados as competências que não lhes sejam vedadas por esta Constituição [...]”.

56 Cf. ADI n. 3.112-1/DF, Min. Rel. Ricardo Lewandowski, Tribunal Pleno, julgado em 2 de maio de 2007.

57 De acordo com a CRFB/88: “Art. 22. Compete privativamente à União legislar sobre: [...] Parágrafo único. Lei complementar poderá autorizar os Estados a legislar sobre questões específicas das matérias relacionadas neste artigo". 
impediria a realização de uma deliberação em sede jurisdicional do caso, avaliando, por exemplo, o impacto da regulação do porte de arma de fogo em função dos crescentes índices de violência urbana do país no comércio interestadual, análise essa permitida pelo negligenciado art. 22, VIII, da CRFB/88. Tal dispositivo é negligenciado pois exigiria rigoroso exame do assunto e, provavelmente, geraria um precedente na Corte. Assim, é mais conveniente inaugurar em nosso regime, embora este já dispense a criação de critérios centralizadores, um novo critério de federalização: a prevalência do interesse geral. Enquanto determinados critérios poderiam passar por uma construção histórica e jurisprudencial de seu sentido, contribuindo para o amadurecimento do regime federativo brasileiro, que em muito se aproxima do regime unitário devido a seu elevado nível de centralização, o Supremo Tribunal Federal prefere estabelecer como parâmetro determinante à sua decisão um critério que nem sequer possui base legal ou conteúdo semântico jurisdicionalmente construído. Esse é um comportamento decisório que não soluciona a dificuldade da incerteza, mas, ao contrário, agrava seu quadro. O termo é composto por três palavras de extrema imprecisão e a fundamentação aduzida no julgamento não foi capaz de combater esse problema - se é que isso foi cogitado ou pretendido.

\section{Federalismo jurisdicional e Federalismo formal}

Inicialmente, é evidente que o caráter formalista do modelo de federalismo encontrado no Brasil aponta como critério de federalização determinante a competência privativa da União Federal para legislar em matéria de direito penal. Nos precedentes mais paradigmáticos dos EUA na seara do federalismo contemporaneamente, a cláusula de comércio desponta como o principal parâmetro decisório adotado pela Suprema Corte, especialmente explorando a avaliação concreta permitida pelo consectário historicamente afirmado na denominada era moderna desse poder do Congresso. ${ }^{58}$ Todos os três leading cases demonstram a influência da demonstração do substancial impacto no comércio interestadual como forma de autorizar a centralização da matéria à federação. De modo similar, a aproximação dessas controvérsias a partir do regime federativo observado atualmente no Brasil parece indicar que também haveria certo predomínio de um critério de federalização: a matéria de direito penal em função do art. 22, I, da CRFB/88.

No entanto, esta não era a única possibilidade de solução da controvérsia no Brasil, embora aparente ser, sem dúvida, a mais simples e intuitiva. Há, no mínimo, mais um critério de

58 Mesmo antes dos precedentes ora abordados, a cláusula de comércio já era compreendida pelos constitucionalistas norte-americanos como um parâmetro determinante em matéria de federalismo: "Commerce Clause jurisprudence has been centrally concerned with these issues and is a natural laboratory for the development of a federalist theory. Our account is essentially structuralist: because the Court is politically vulnerable to Congress and the President, it has rarely attempted to construe the Commerce Clause to limit congressional authority" (ESKRIDGE JR.; FEREJOHN, 1994, p. 1359). 
federalização que poderia servir como alternativa à centralização de tais regulamentações no Brasil. Quanto a esse critério, note-se a referência direta à tradição constitucional norteamericana, não obstante ser, na prática, absolutamente inócuo e negligenciado: “Art. 22. Compete privativamente à União legislar sobre: [...] VIII - comércio exterior e interestadual; [...]”. Isso significa que todas essas questões também poderiam ser submetidas a análises mais concretas e minuciosas do que uma automática centralização da solução nas mãos da União Federal. Em primeiro lugar, existem mais critérios de federalização à disposição dos interessados em federalizar tais matérias e, em segundo lugar, há alguns critérios tão genéricos a ponto de abranger todo o espectro de distintos ramos do direito e tão invariáveis a ponto de não admitir uma avaliação das razões existentes para manter ou não a competência sob a autonomia legislativa dos estados. Tais situações tornam a forma federativa brasileira particularmente caracterizada por uma forte centralização, enquanto os EUA, em contrapartida, encontram-se limitados a, praticamente, um único e determinante parâmetro decisório capaz de retirar a autoridade de seus estados. Asseverando esse quadro, o julgamento da ADI n. 3.112-1/DF, relativa à inconstitucionalidade formal do Estatuto do Desarmamento (Lei Federal n. 10.826/2003), demonstrou haver também aleatoriedade na escolha do critério de federalização determinante ao caso - "predominante interesse geral". 59

Por meio destas singelas comparações, é possível constatar que, de um lado, o federalismo jurisdicional norte-americano parte do pressuposto de que a incerteza sempre existirá, e que a única forma segura de se preservar um regime federativo é a discussão crítica da matéria, avaliando, com extremo rigor, se haveria fundadas razões para conduzi-la à centralização. Por outro lado, o federalismo formal, envolvido em uma ingênua concepção de que a completude de seu sistema de distribuição de competências corresponde a um grau mais elevado de segurança jurídica capaz de afastar a incerteza e eliminar a chance de instauração de dilemas federativos, prefere centralizar a matéria de plano. Isso significa que, na dúvida, o Brasil centraliza, enquanto os EUA deliberam, enfrentando com seriedade a questão e, sobretudo, respeitando o que já fora outrora definido. A falta de deliberação no Brasil, quando o caso é solucionado com base em um critério formal cuja estratégia é, na verdade, centralizar como pressuposto, impede que se promova uma construção histórica dos parâmetros determinantes no interior da estrutura federativa do Estado.

Agravando a questão, nossa Corte Constitucional prefere se aventurar na inovação de critérios de federalização genéricos e de matriz semântica absolutamente indefinida e desprovida de uma consolidação histórica, aprofundando o panorama de centralização política de nosso regime federativo e ampliando a insegurança decorrente da aplicação de parâmetros que mais parecem servir à conveniência e ao casuísmo dos eminentes julgadores. Por mais que

59 Cf. ADI n. 3.112-1/DF, Min. Rel. Ricardo Lewandowski, Tribunal Pleno, julgado em 2 de maio de 2007. 
sempre permaneça a hipótese da incerteza, essa diz respeito às controvérsias práticas que hão de surgir ao longo da experiência democrática de um país, não aos parâmetros que se destinam a resolvê-las.

O modelo jurisdicional norte-americano, ao contrário, permitiu que o regime federativo pudesse passar por um profundo amadurecimento, de modo que um único critério de federalização protagoniza a dinâmica de centralização e descentralização, contando com um reconhecimento sedimentado pelos julgadores envolvidos na atividade da Suprema Corte e em que a sociedade e os demais atores políticos depositam uma expressiva confiança. Com isso, preserva-se a autonomia dos estados, ao menos de modo mais significativo do que se observa no regime quase unitário de nosso federalismo formal.

\section{CONCLUSÃo}

A presente pesquisa, a partir dos precedentes paradigmáticos recentes da Suprema Corte dos EUA em matéria de federalismo, promoveu uma confrontação entre os modelos norteamericano e brasileiro. A abordagem de temas polêmicos como a violência motivada por gênero - United States vs. Morrison (2000) -, o uso medicinal da maconha - Gonzales vs. Raich (2005) - e o porte de arma de fogo em zona escolar - United States vs. Lopez (1995) - e sua comparação com o cenário brasileiro permitiram que se constatasse uma diferença notável entre esses dois modelos no que tange à centralização política. ${ }^{60}$

Com efeito, uma pesquisa somente orientada a comprovar que o regime federativo brasileiro é mais centralizado do que o norte-americano não tenderia a trazer nada de original ou inovador. O que se pretendeu demonstrar, no entanto, foi o especial enfoque que o tema federalismo pode receber pela via jurisdicional. Nos EUA, a preservação de um regime que confere ampla autonomia aos estados deve muito à atuação da Suprema Corte em sua postura invariável em impedir que a autoridade do Congresso fosse hipertrofiada de modo injustificado. ${ }^{61} \mathrm{O}$ comportamento dessa Corte pode ser caracterizado, ao redor do tema federalismo, como predominantemente conservador, pois a coerência na utilização dos parâmetros decisórios a conduziu, inclusive, a tomar decisões altamente impopulares, como negar prestação jurisdicional a uma mulher vítima de estupro em concurso de agentes, impedir que pacientes em grave quadro clínico pudessem dar continuidade a seus tratamentos médicos com a maconha, além de invalidar legislação federal proibindo o porte de arma de fogo em zonas escolares. ${ }^{62}$

60 Cf. United States vs. Morrison, 529 U.S. 598 (2000); Gonzales vs. Raich, 545 U. S. 1 (2005); e United States vs. Lopez, 514 U.S. 549 (1995).

61 Em relação a fenômenos institucionais de atrofia e hipertrofia de poderes constitucionais, bem como a existência da chamada soma zero entre tais poderes em diferentes instituições, ver Vermeule (2011b).

62 Alguns autores trabalham com o risco de as questões federalistas serem solucionadas pelas Cortes a partir de determinada compreensão política predominante em ocasiões oportunas. Particularmente, Keith 
Ao final das análises, parece plausível sustentar que o Brasil possui um modelo de federalismo altamente centralizado, em que há uma grande pluralidade de critérios alternativos de federalização. Isso torna mais fácil e propensa a ocorrência da centralização, pois há distintos fatores que a permitem. Se não bastasse a pluralidade de critérios de federalização presente no contexto brasileiro, eles são significativamente abrangentes e permitem que a centralização seja um ponto de partida. Por fim, complementando a ênfase conferida à federação, no Brasil, o Supremo Tribunal Federal soluciona seus casos de federalismo de modo aleatório, inclusive, afirmando parâmetros decisórios no mínimo imprecisos e inconsistentes para retirar autoridade legislativa dos estados. O caso norte-americano, por sua vez, não se baseia em um regime formal de distribuição altamente detalhada como ocorre no Brasil. Nos EUA, a consolidação do regime federativo se desenvolve, destacadamente, pela via jurisdicional. Admitindo a incerteza que pode decorrer das previsões normativas incompletas da norma constitucional, as controvérsias suscitadas são enfrentadas pela Suprema Corte que, reafirmando um parâmetro decisório que se mostrou determinante em matéria de federalismo - a cláusula de comércio, notadamente na autoridade do Congresso de regular o comércio interestadual -, evidencia um nível muito reduzido de centralização. Enquanto a Suprema Corte norte-americana aplica, basicamente, um único critério de federalização para solucionar seus dilemas federativos, o Brasil conta com um repertório extenso de critérios, cada qual consubstanciando regras genéricas e invariáveis - o que inclui o casuísmo do "predominante interesse geral" - que tendem a preferir, de plano, a centralização política em detrimento da autonomia dos estados ou mesmo da relevância de se deliberar quanto à necessidade de centralização.

Whittington elaborou o conceito de federalismo ofensivo na atividade jurisdicional, caracterizando a postura da Corte de Rehnquist como tal: "The federalism offensive can best be understood as a product of the Court's taking advantage of a relatively favorable political environment to advance a constitutional agenda of particular concern to some individuals within the Court's conservative majority. The Court has moved carefully but steadily to reestablish some federalism-based constraints on the national government. [...] Nonetheless, the Lopez Court has been unusually active in striking down acts of Congress and reorienting constitutional law. In doing so, the Court has been an autonomous agent of constitutional change. The Court has seized the political opportunities that have presented themselves to advance the Court's own understanding of the Constitution. The Court has been opportunistic. [...] The Court is not alone in doing so. But along with other political actors, the Rehnquist Court is participating in a political process of constitutional change" (WHITTINGTON, 2001, p. 479, 519-520). 
JUDICIALIZAÇÃO DO FEDERALISMO E FEDERALISMO FORMAL : $\mathbf{2 4 7}$

\section{NOTA DE AGRADECIMENTO}

Este artigo foi elaborado no âmbito do Laboratório de Estudos Teóricos e Analíticos sobre o Comportamento das Instituições (Letaci), vinculado ao Programa de Pós-Graduação em Direito (PPGD) e à Faculdade Nacional de Direito (FND) da Universidade Federal do Rio de Janeiro (UFRJ), financiado pelo Conselho Nacional de Desenvolvimento Científico e Tecnológico (CNPq), no âmbito da concorrência do Edital Universal 14/2013, e pela Fundação Carlos Chagas Filho de Amparo à Pesquisa do Estado do Rio de Janeiro (Faperj), no âmbito da concorrência do Edital 41 /2013, Programa de Apoio a Grupos Emergentes do Estado do Rio de Janeiro.

\section{REFERÊNCIAS BIBLIOGRÁFICAS}

ALTHOUSE, Ann. Enforcing Federalism After United States v. Lopez. Arizona Law Review, v. 38, n. $793,1996$.

ARAÚJO, Marcelo Labanca Corrêa de. Jurisdição constitucional e federação: o princípio da simetria na jurisprudência do STF. Rio de Janeiro: Elsevier, 2009.

BALMAN, Steven. Constitutional Irony: Gonzales v. Raich, Federalism and Congressional Regulation of Intrastate Activities under the Commerce Clause. Tulsa Law Review, v. 41, n. 2, 2005.

BANSAL, Preeta. The Supreme Court's Federalism Revival and Reinvigorating the "Federalism Deal”. St. John's Journal of Legal Commentary, v. 21, n. 2, 2007.

BARNETT, Randy. Limiting Raich. Lewis \& Clarck Law Review, v. 9, n. 4, 2005.

The Original Meaning of Commerce Clause. The University of Chicago Law Review, v. 68, n. $101,2001$.

BERMAN, José Guilherme. Repercussão geral no recurso extraordinário: origens e perspectivas. Curitiba: Juruá, 2009. 
CARVAlHO, José Murilo de. Os bestializados: o Rio de Janeiro e a República que não foi. São Paulo: Companhia das Letras, 1987.

CHEMERINSKY, Erwin. Appearances Can Be Deceiving: October Term 2013 Moved the Law to the Right. University of California Legal Studies Research Paper Series, n. 2014-61, 2014.

The Values of Federalism. Florida Law Review, v. 47, n. 4, 1995.

CLAYTON, Cornell; PICKERILL, Mitchell. Guess What Happened on the Way to Revolution? Precursors to the Supreme Court's Federalism Revolution. Publius: The Journal of Federalism, v. 34, n. 3, 2004.

COSTA, Elder Lisboa Ferreira da. O gênero no direito internacional: discriminação, violência e proteção. Belém: Paka-Tatu, 2014.

CROWELL, David. Gonzales v. Raich and the Development of Commerce Clause Jurisprudence: is the Necessary and Proper Clause the Perfect Drug? Rutgers Law Journal, v. 38, n. 251, 2006.

DEVINS, Neal. How Congress Paved the Way for the Rehnquist Court's Federalism Revival: Lessons from the Federal Partial Birth Abortion Ban. St. John's Journal of Legal Commentary, v. 21, n. 2, 2007.

ESKRIDGE, JR., William; FEREJOHN, John. The Elastic Commerce Clause: A Political Theory of American Federalism. Vanderbilt Law Review, v. 47, n. 1355, 1994.

GRAGLIA, Lino. Lopez, Morrison, and Raich: Federalism in the Rehnquist Court. Harvard Journal of Law and Public Policy, v. 31, n. 761, 2008.

GERKEN, Heather. Justice Kennedy and the domains of Equal Protection. Harvard Law Review, v. 121, n. 104, 2007.

HALL, Kermit (Org.). The Oxford Companion to the Supreme Court of the United States. 2. ed. New York: Oxford University Press, 2005.

HAMILTON, Alexander; MADISON, James; JAY, John. The Federalist Papers. Eletronic Classics Series Publication, Pennsylvania State University, 2001.

McGIMSEY, Diane. The Commerce Clause and Federalism after Lopez and Morrison: The Case for Closing the Jurisdictional-Element Loophole. California Law Review, v. 90, n. 9, 2002. 
MARTIN, Andrew; QUINN, Kevin; EPSTEIN, Lee. The Median Justice on the United States Supreme Court. North Carolina Law Review, v. 83, n. 1275, 2005.

MARTIN, Jil. United States v. Morrison: Federalism against the will of States. Loyola University Chicago Law Review, v. 32, n. 9, 2000.

MEIRELLES, Hely Lopes. Direito administrativo brasileiro. 16. ed. São Paulo: Revista dos Tribunais, 1991. Direito municipal brasileiro. 7. ed. São Paulo: Malheiros, 2006.

POSNER, Eric; VERMEULE, Adrian. The Executive Unbound: after the madisonian republic. New York: Oxford University Press, 2011.

SILVA, José Afonso da. Curso de direito constitucional positivo. 28. ed. São Paulo: Malheiros, 2007.

STACY, Tom. What's Wrong with Lopez. Kansas Law Review, v. 44, n. 243, 1996.

TUSHNET, Mark. A Court Divided: the Rehnquist Court and the Future of Constitutional Law. New York: W.W. Norton \& Company, 2005.

. A Republican Chief Justice. Michigan Law Review, v. 88, n. 1326, 2000.

VERMEULE, Adrian. Mechanisms of Democracy: institutional design writ small. New York: Oxford University Press, 2011a.

The Atrophy of Constitutional Powers. Harvard Law School Public Law and Legal Theory Working Papers Series, n. 11-07, 2011b.

VIRELLI, Louis; LEIBOWITZ, David. "Federalism Whether They Want it or Not": The New Commerce Clause Doctrine and the Future of Federal Civil Rights Legislation after United States v. Morrison. Journal of Constitutional Law, v. 3, n. 3, 2001.

WhitTINGTON, Keith. Taking What They Give Us: Explaining The Court's Federalism Offensive. Duke Law Journal, v. 51, n. 477, 2001.

YOUNG, Ernest. The Conservative Case for Federalism. The George Washington Law Review, v. 74, n. $874,2006$. 
Mestrando pelo Programa de Pós-Graduação em Direito da Universidade FEDERAL do RIO dE JANEIRO (UFRJ).

henriquerangelclagmail.com

\section{Alexandre Fadel}

Professor de Direito Constitucional da Universidade da Amazônia, da Faculdade de BelÉm e da Faculdade Metropolitana da Amazônia.

pinhofadeldagmail.com

Bianca Neri

Mestranda em Direito Público pela Universidade Estácio DE SÁ E ADVOGADA.

biancagneridgmail.com

\section{Carlos Bolonha}

Professor adjunto da Faculdade Nacional de Direito E professor permanente do Programa de Pós-Graduação em Direito da Universidade Federal do Rio de Janeiro (UFRJ).

Diretor do Centro de Pesquisa e Documentação da Ordem dos Advogados do Brasil, seccional do Rio de Janeiro.

bolonhacarlosigmail.com 